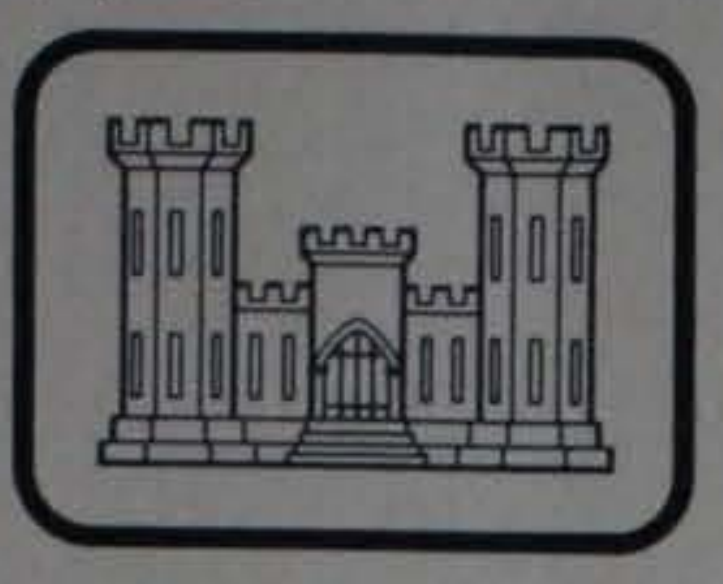

MISCELLANEOUS PAPER HL-79-6

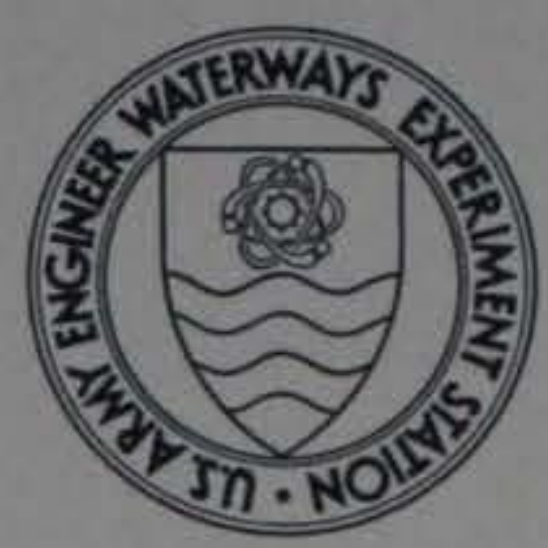

\title{
RECENT AUTOMATION CHANGES IN MODEL VELOCITY ANALYSES AND DATA ACQUISITION BY MINIATURE PRICE METERS
}

by

Donald L. Durham, Homer C. Greer III, Kent A. Turner

Hydraulics Laboratory

U. S. Army Engineer Waterways Experiment Station

P. O. Box 631, Vicksburg, Miss. 39180

May 1979

Final Report

Approved For Public Release; Distribution Unlimited

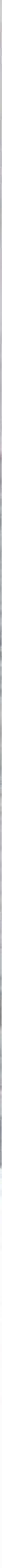

Prepared for U.S. Army Engineer District, Charleston

Charleston, South Carolina 29402

Wao himeton, D.C.

LIBRARY BRAWCH

TECHNICAL MFORMATION CENTER

US ARMY ENGINEER WATERWAYS EXPERIMENT STATION

vicksBure. miserssippI 


\section{DEPARTMENT OF THE ARMY \\ WATERWAYS EXPERIMENT STATION. CORPS OF ENGINEERS \\ P. O. BOX 631 \\ VICKSBURG, MISSISSIPPI 39180}

WESHH

28 August 1979

\section{Errata Sheet}

No. 1

\section{RECENT AUTOMATION CHANGES IN MODEL VELOCITY ANALYSES}

AND DATA ACQUISITION BY MINIATURE PRICE METERS

Miscellaneous Paper HL-79-6

May 1979

1. On cover of report, change last two lines to read:

Prepared for Office, Chief of Engineers, U. S. Army

Washington, D. C. 20314

2. On the Form 1473, change Block 11 to read:

Office, Chief of Engineers, U, S. Army

Washington, D. C. 20314

3. On page 1 , change 1 ines 5 and 6 to read:

This report was published under the Office, Chief of Engineers, Civil Works Research Unit on Model Sensor Development.

4. On facsimile catalog card, last page in report, change 1 ines 10 and 11 to read:

Prepared for Office, Chief of Engineers, U. S. Army Washington, D. C. 


\section{REPORT DOCUMENTATION PAGE}

1. REPORT NUMBER

2. GOVT ACCESSION NO.

READ INSTRUCTIONS

BEFORE COMPLETING FORM

Miscellaneous Paper HL-79-6

4. TITLE (and Subtitie)

RECENT AUTOMATION CHANGES IN MODEL VELOCITY ANALYSES AND DATA ACQUISITION BY MINIATURE PRICE METERS

5. TYPE OF REPORT \& PERIOD COVERED

Final report

7. AUTHOR(a)

6. PERFORMING ORG. REPORT NUMBER

8. CONTRACT OR GRANT NUMBER(B)

Donald L. Durham

Homer C. Greer III

Kent A. Turner

9. PERFORMING ORGANIZATION NAME AND ADDRESS

U. S. Army Engineer Waterways Experiment Station

Hydraulics Laboratory

P. 0. Box 631, Vicksburg, Miss. 39180

11. CONTROLLING OFFICE NAME AND ADPRESS U. As Army Engineel Distriet, Gharieston

P. O. BOX 919

Charleston, S. C. 29402 Washiua ton, D.C. 20314

14. MONITORING AGENCY NAME \& ADDRESS(If difforent from Controlling Office)

10. PROGRAM ELEMENT, PROJECT, TASK AREA \& WORK UNIT NUMBERS

12. REPORT DATE

May 1979

13. NUMBER OF PAGES

62

15. SECURITY CLASS. (of this report)

Unclassified

15a. DECLASSIFICATION/DOWNGRADING

16. DISTRIBUTION STATEMENT (of this Report)

Approved for public release; distribution unlimited.

17. DISTRIBUTION STATEMENT (of the abstract ontered in Block 20, if different from Report)

18. SUPPLEMENTARY NOTES

19. KEY WORDS (Continue on reverse side if necessary and identify by block number)

Automation

Current meters

Data acquisition

Data processing
Digital recording

Measuring instruments

Velocity

20. ABSTRACT (Contiaue an roverae side if necresary and tdentify by block number)

Recent automation of acquisition and analysis of velocity data collected by Price meters is presented in this report. Recent improvements to the fiber optic elements for the Price meter and development of electronic/binary counting circuits are discussed. A general description of a portable digital recording system and detailed documentation of its operating procedures are presented. In addition, documentation is provided for (a) the format of the output magnetic

(Continued) 
20. ABSTRACT (Continued).

tape generated by the portable digital recording system, and (b) computer (H635) programs for reading and demultiplexing data on magnetic tape, editing and scaling velocity data, and reducing velocity data to a standard format for use in analysis programs and technical reports. 
The automation changes in model velocity acquisition and analysis, which are documented by this report, were performed in support of the hydraulic model investigation of Little River Inlet, South Carolina, which was authorized by the U. S. Army Engineer District, Charleston. This report was published under the Civil Works Resefor on Work Unit on Model Sensor Development. 4 nit on model Lensor $D$ eveloyment

The study was conducted in the Hydraulics Laboratory of the U. S. Army Engineer Waterways Experiment Station (WES) during the period July 1974 to July 1975 under the direction of Mr. H. B. Simmons, Chief of the Hydraulics Laboratory, and Dr. R. W. Whalin, Chief of the Wave Dynamics Division (WDD) and under the general supervision of $\mathrm{Mr}$. C. E. Chatham, Chief of the Harbor Wave Action Branch (HWAB).

The work was performed by Dr. D. L. Durham, Messrs. K. A. Turner, and C. W. Coe of HWAB, and Messrs. H. C. Greer and J. L. Pickens of the Instrumentation Services Division (ISD). This report was prepared by Dr. Durham (WDD) and Messrs. Greer (ISD) and Turner (WDD).

Directors of WES during the conduct of this work and the preparation and publication of this report were COL G. H. Hilt, CE, and COL John L. Cannon, CE. Technical Director was Mr. F. R. Brown. 
PREFACE . . . . . . . . . . . . . . . . . . . .

CONVERSION FACTORS, U. S. CUSTOMARY TO METRIC (SI)

UNITS OF MEASUREMENT .......................... 3

PART I: INTRODUCTION . . . . . . . . . . . . . . . . 4

Model Automation Efforts . . . . . . . . . . . 4

Purpose of Report ............... . . . 6

PART II: TIDAL CURRENT RECORDING SYSTEM . . . . . . . . 7

General . . . . . . . . . . . . . . . 7

Transducer . . . . . . . . . . . . . . . 7

Counting Circuit.......................... 11

Digital to Analog Converter . . . . . . . . . . . 13

Digital Recorder................ . . 15

Digital Electronic Clock . . . . . . . . . . . . . 19

Operational Procedures ............... 21

PART III: TIDAL VELOCITY DATA ANALYSES . . . . . . . . . 27

Outline of Procedures .............. . . 27

Original Tape of Tidal Velocity . . . . . . . . . . 28

Preprocessor . . . . . . . . . . . . . . . 31

Data Processor . . . . . . . . . . . . . 36

PART IV: SUMMARY ....................... . . . 40

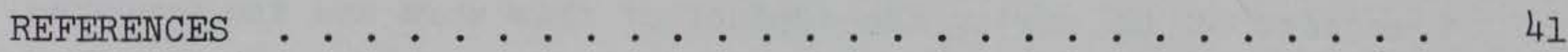

TABLES 1-4

APPENDIX A: DIGITAL TO ANALOG CONVERTER SPECIFICATIONS . . . . AI

APPENDIX B: DETAILS OF DIGITAL RECORDING SYSTEM . . . . . . BI

APPENDIX C: SAMPLES OF PREPROCESSOR OUTPUT . . . . . . . . . . C1

APPENDIX D: SAMPLES OF PROCESSOR OUTPUT . . . . . . . . . DI 
U. S. customary units of measurement used in this report can be converted to metric (SI) units as follows:

\begin{tabular}{llll}
\multicolumn{1}{c}{ Multiply } & By & & \multicolumn{1}{c}{ To Obtain } \\
Fahrenheit degrees & $5 / 9$ & & Celsius degrees or Kelvins* \\
feet & 0.3048 & & metres \\
feet per second & 0.3048 & & metres per second \\
inches & 2.54 & centimetres
\end{tabular}

* To obtain Celsius (C) temperature readings from Fahrenheit (F) readings, use the following formula: $C=(5 / 9)(F-32)$. To obtain Kelvin $(K)$ readings, use: $K=(5 / 9)(F-32)+273.15$. 


\section{AND DATA ACQUISITION BY MINIATURE PRICE METERS}

\section{PART I: INTRODUCTION}

\section{Model Automation Efforts}

1. Since 1974, considerable effort has been expended by personnel of the U. S. Army Engineer Waterways Experiment Station (WES), Wave Dynamics Division (WDD) of the Hydraulics Laboratory, and the Operations Branch of the Instrumentation Services Division (ISD) in automating data acquisition, data analyses, and model controls for physical hydraulic wave models of harbors and tidal inlets. Basically these efforts have been devoted to:

a. Design and development of automated systems for acquisition of model data (wave and tidal heights, temperature, and water level) and for model controls (wave and tide generators).

b. Automation of data reduction and analyses.

2. There are presently three automated systems for hydraulic models in the Hydraulics Laboratory. One system ${ }^{1}$ developed several years ago services the New York Harbor model in the Estuaries Division of the Hydraulics Laboratory. The other two systems, 2,3,4 are operational on various wave models in WDD. These automated systems have been given the title "Automated Data Acquisition and Control System" (whose acronym is ADACS) and have two primary functions: (a) automated acquisition of wave data in a format (magnetic tape or disc) compatible with computer reduction and analyses, and (b) automated control of sensor calibrations and of the wave and tide generators. The system configuration of ADACS consists of the following subsystems:

a. Digital data recording and controls.

b. Analog recorders and channel selection circuits.

c. Sensors and interfacing equipment.

d. Wave or tide generators and control equipment. 
3. The digital data recording and control subsystem is basically a minicomputer with the appropriate characteristics and peripheral devices. The analog subsystem is basically a backup for the first subsystem. Details of these two subsystems are presented in References 2 and 3 .

4. The sensor subsystem includes the following major components: a. Fifty wave-height sensors and stands.

b. Fifty channels of signal conditioning equipment.

c. Forty-eight channels of tidal height information using one pressure cell and a scanivalue arrangement.

d. Water and air temperature sensors.

e. Power supplies.

f. Manual and automatic calibration equipment.

5. The last subsystem, wave and tide generators and control, is not completely implemented in the present configuration of both ADACS. Upon completion, the wave generators will utilize electrohydraulic actuators for driving a wave board instead of mechanically gear-driven wave boards. The displacement of the electrohydraulic actuators will be programmed by a varying analog voltage generated by ADACS. Thus, the period and amplitude of the actuator displacement and, in turn, the generated wave will be controlled automatically. ${ }^{5}$ Presently, Start/Stop controls are available for mechanical wave generators; however, controls for wave periods and amplitude must be set manually. For control of tide generators, ADACS provides a harmonic analog voltage, which is composed of a specified number of tidal harmonic components (amplitude and frequency), to an electrohydraulic assemblage ${ }^{6}$ controlling the water level in a tide model.

6. With advances to the above sophisticated procedures for model controls and data acquisition/analyses, the need for improvements in model transducers and sensors has become more evident. In an attempt to improve model sensors used in wave and tidal inlet models, personnel of WDD and ISD began a sensor evaluation and development program. Initially, wave and tide elevation sensors are being scrutinized. The results of these studies are to be published in future reports. In 
addition to the above wave and tidal height sensors and automated efforts, preliminary efforts were initiated to provide better transducers and to automate procedures presently used to acquire model velocity data. Two types of electromagnetic current meters that provide low threshold velocities and direction of flow in physical hydraulic models are being evaluated as to designs, model applications, and ADACS interface. Until new velocity sensors with the desired characteristics can be provided, the manual procedures of acquiring model velocity data by miniature Price meters and of analyzing those data are in drastic need of improvement.

\section{Purpose of Report}

7. The purpose of this report is to document recent automation changes to past procedures of acquiring and analyzing model velocity data by miniature Price meters. ${ }^{7}$ The concept of these meters emitting electric pulses as the cups pass a fiber optics element was implemented several years ago on Masonboro Inlet Model Study. 6 The sensors on that model were interrogated directly by an ADACS. Price meters in various forms have been used for many years by the Hydraulics Laboratory to collect velocity data in physical hydraulic models. In fact, various types of these sensors are manufactured at WES. It is not the intent of this report to document specifically the miniature Price meters. However, this report documents:

a. Recent improvements to the fiber optic elements and the counting circuits.

b. The description of a portable digital recording system and its operational procedures.

c. Reduction and analyses of the collected data to a standard format presently used for technical reports. 


\section{General}

8. The recording system (Figures 1 and 2 ) is designed to detect water currents in hydraulic tidal models and to record the raw data on a digital magnetic tape in a computer-compatible format.

9. At the present time, the best water current transducer available for use is a cup-driven Price meter; however, much work is being done to find a more suitable meter for automatic data acquisition and for better accuracy.

10. In general, pulses generated by the Price meter are counted by an electronic counter in a digital format for a preset interval of time and recorded by a digital magnetic tape recorder. The information recorded on the magnetic tape is synchronized with prototype time so that parameters recorded on other recorders can be compared in the time domain.

\section{Transducer}

11. The transducer (Figures 3 and 4) for this system is a Pricetype current meter modified to detect small water currents as low as $0.05 \mathrm{fps}^{*}$ in tidal models. For maximum sensitivity and minimum impedance to tidal currents, the diameter of the cone wheel is limited to $0.06 \mathrm{ft}$, the $0.04-\mathrm{ft}$-diam cones are constructed from plastic, and the axle of the cone wheel is supported with jewel bearings.

12. The transducer was further modified** by painting a white spot in the black field so that fiber optics could be used to sense the revolutions per minute of the cup used. In operation, a light is directed through a fiber optic element toward the white dots on the

* A table of factors for converting U. S. customary units of measurement to metric (SI) units is presented on page 3.

* D. H. Terrell, Physicist, Dynamics Branch, Instrumentation Service Division, U. S. Army Engineer Waterways Experiment Station. 


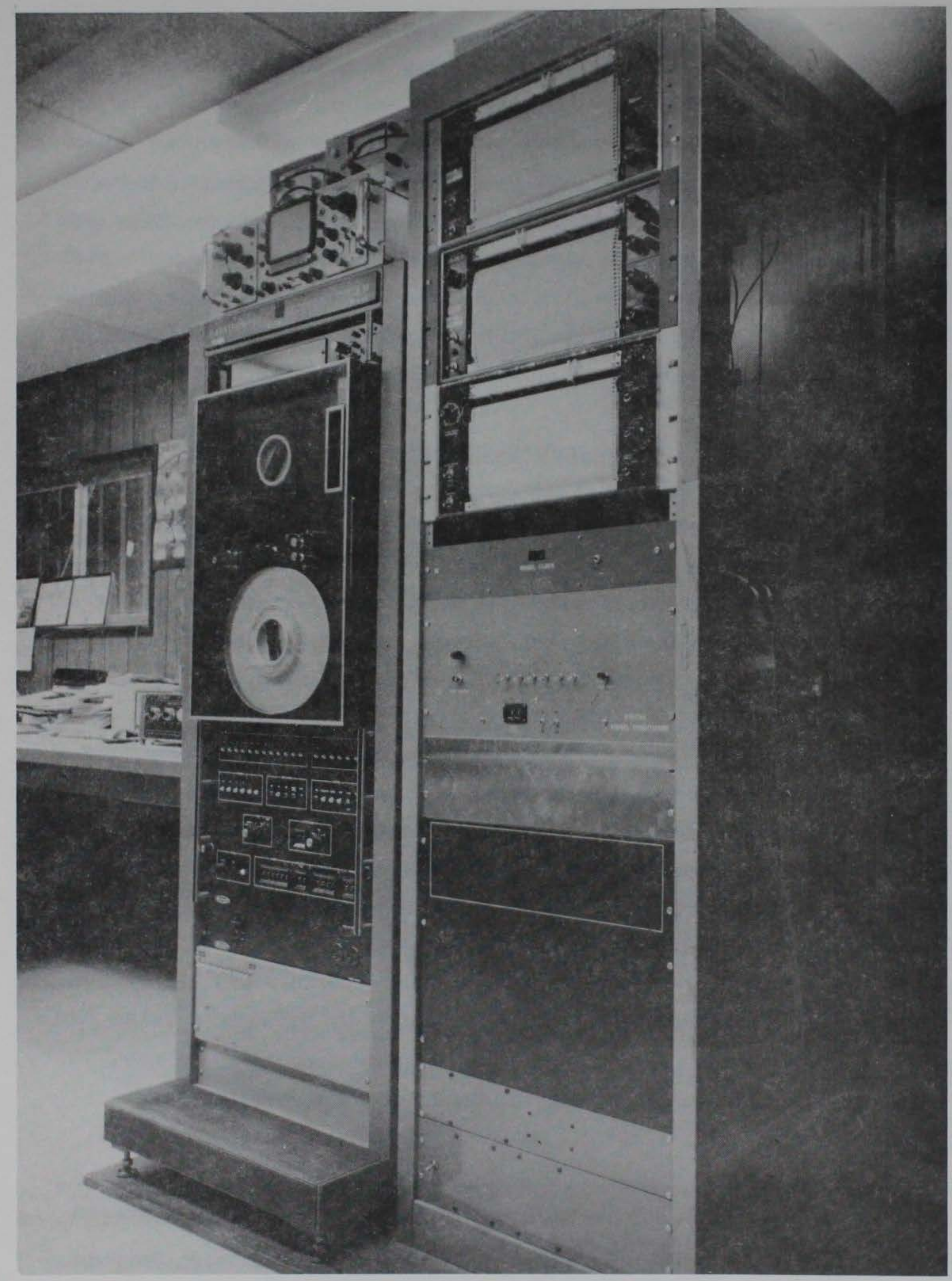

Figure 1. Data Acquisition System 


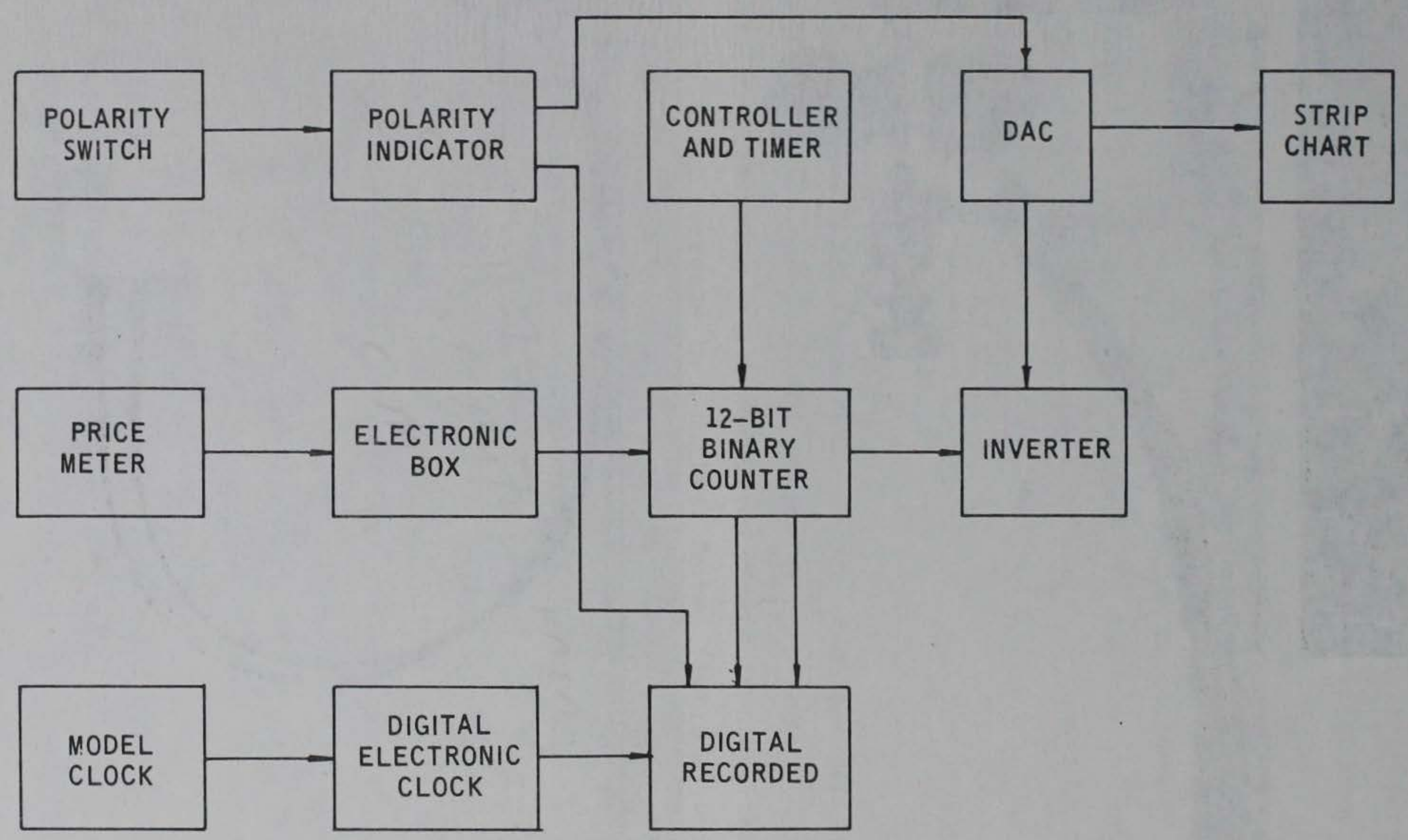

Figure 2. Flow chart for Automated Velocity Recording System 


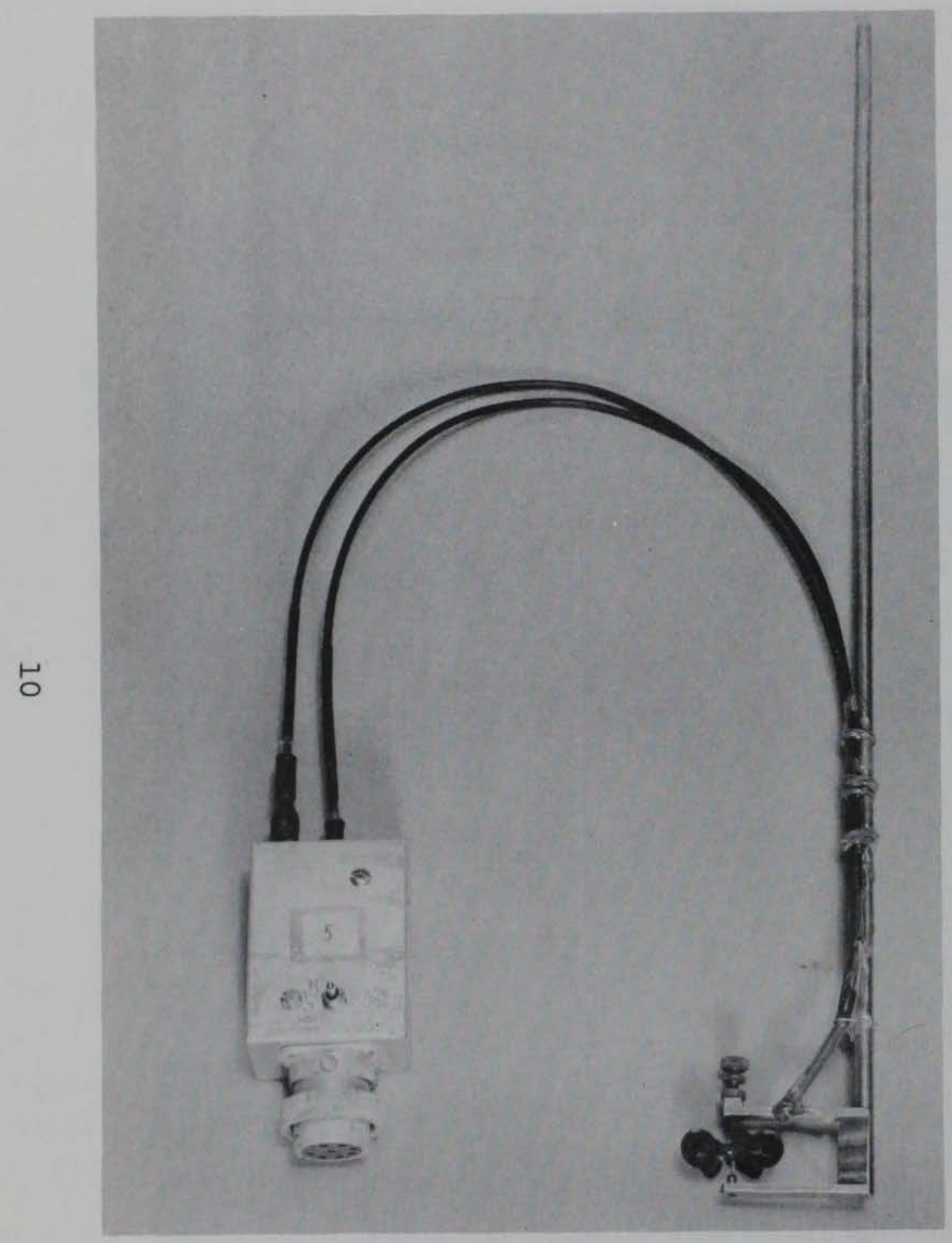

Figure 3. Modified Price meter with photoelectric circuitry

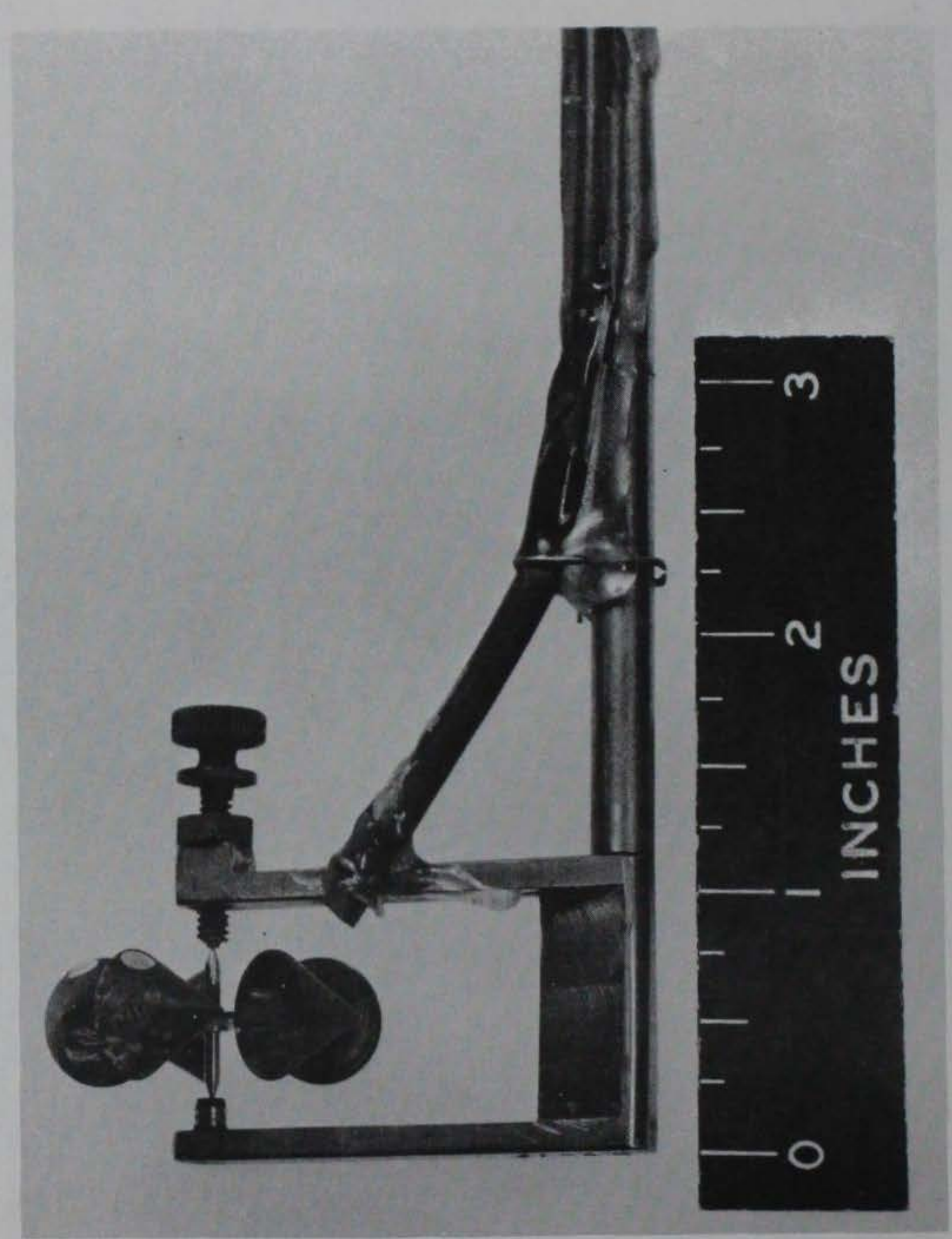

Figure 4. Modified Price meter with fiber optics 
cones. As the cone wheel rotates, light is reflected from the white spots to form a pulse train where the number of pulses per second is proportional to the water current. This pulse train is directed through a return fiber optic to a photo cell which converts light energy to electrical energy.

13. The Price meter is a unidirectional device and it is necessary for it to be rotated 180 degrees when the tidal current changes from ebb to flood and flood to ebb. The time of rotation is decided by a technician experienced in tidal model technology. At the time of rotation, a polarity switch located near the electronics box is thrown by the technician to properly polarize the data being recorded.

\section{Counting Circuit}

14. The current meter produces an output of pulses per second which are proportional to water current in feet per second. An electronic counter, totalizing over a specified period of time, can be used to measure the tidal currents in a digital format (Table l) which can readily be recorded on a computer-compatible magnetic tape.

15. The pulses from the Price meter are received at the input of the counter (Figures 5 and 6 ), conditioned to be compatible with TTL logic, and counted in a 12-bit unipolar natural binary format for a predetermined time interval.

16. The counting circuit employs three integrated circuits $7493 \mathrm{~N}$, ripple-through binary counters. The 12-bit binary output of this counter is connected to the inputs of three integrated-circuit-quad latches (registers), $7475 \mathrm{~N}$, where the data are stored to be strobed and recorded by the digital recorder. The counters and registers are synchronized with a timing-control circuit (Figures 7 and 8) that updates the binary count registers and then resets the counters. The time required to store data and reset the counters, and for the counters to resume their counting is negligible; therefore no pulses or data are lost. The interval during which the counter totalizes the input pulses from the Price meter can be set with thumbwheel switches for any time 


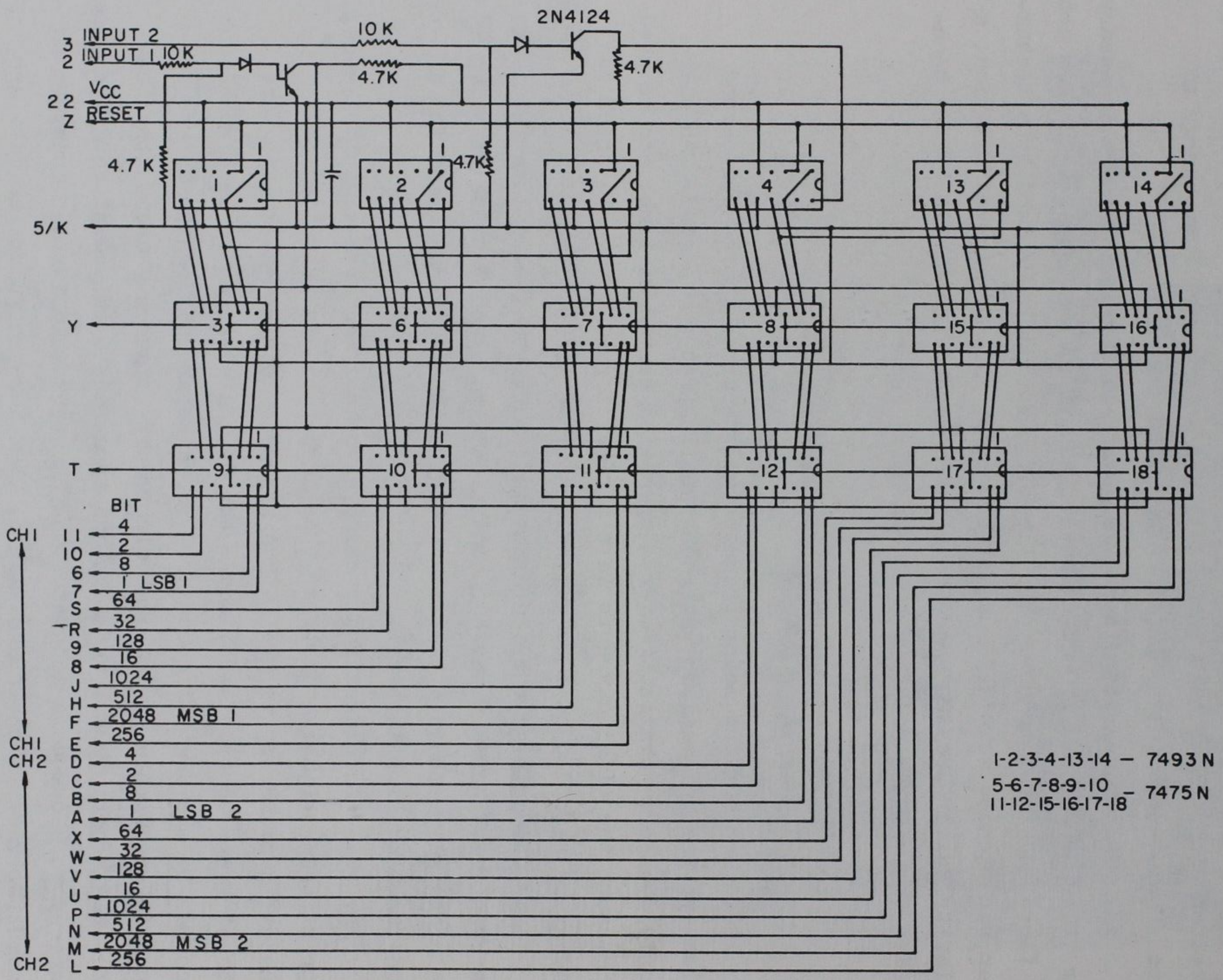

Figure 5. Schematic of binary counter 


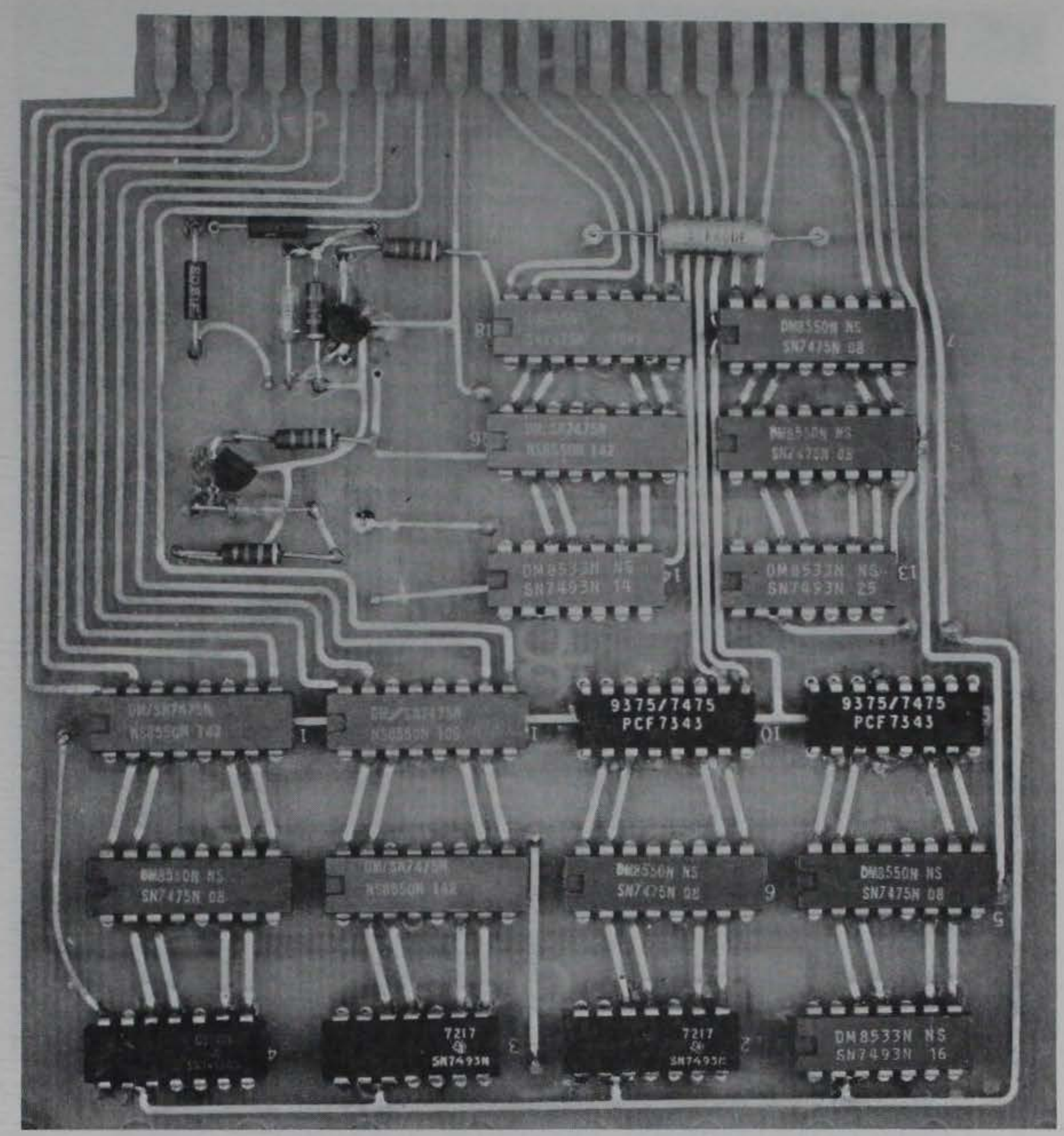

Figure 6. Printed circuit board of binary counter duration from 1 to $99 \mathrm{sec}$. Since the registers update at the end of each time interval ( 1 to $99 \mathrm{sec}$ ), the possibility of the digital recorder acquiring data while the registers are updating is avoided by the insertion of a second register between the first register and the recorder. This second register updates with the first register, except when the digital recorder is acquiring data. During this period of time the second register is inhibited. The digital recorder updates its registers in nanoseconds so this inhibit time is minimal.

\section{Digital to Analog Converter (DAC)}

17. The output of the counter card is coupled through inverters to 


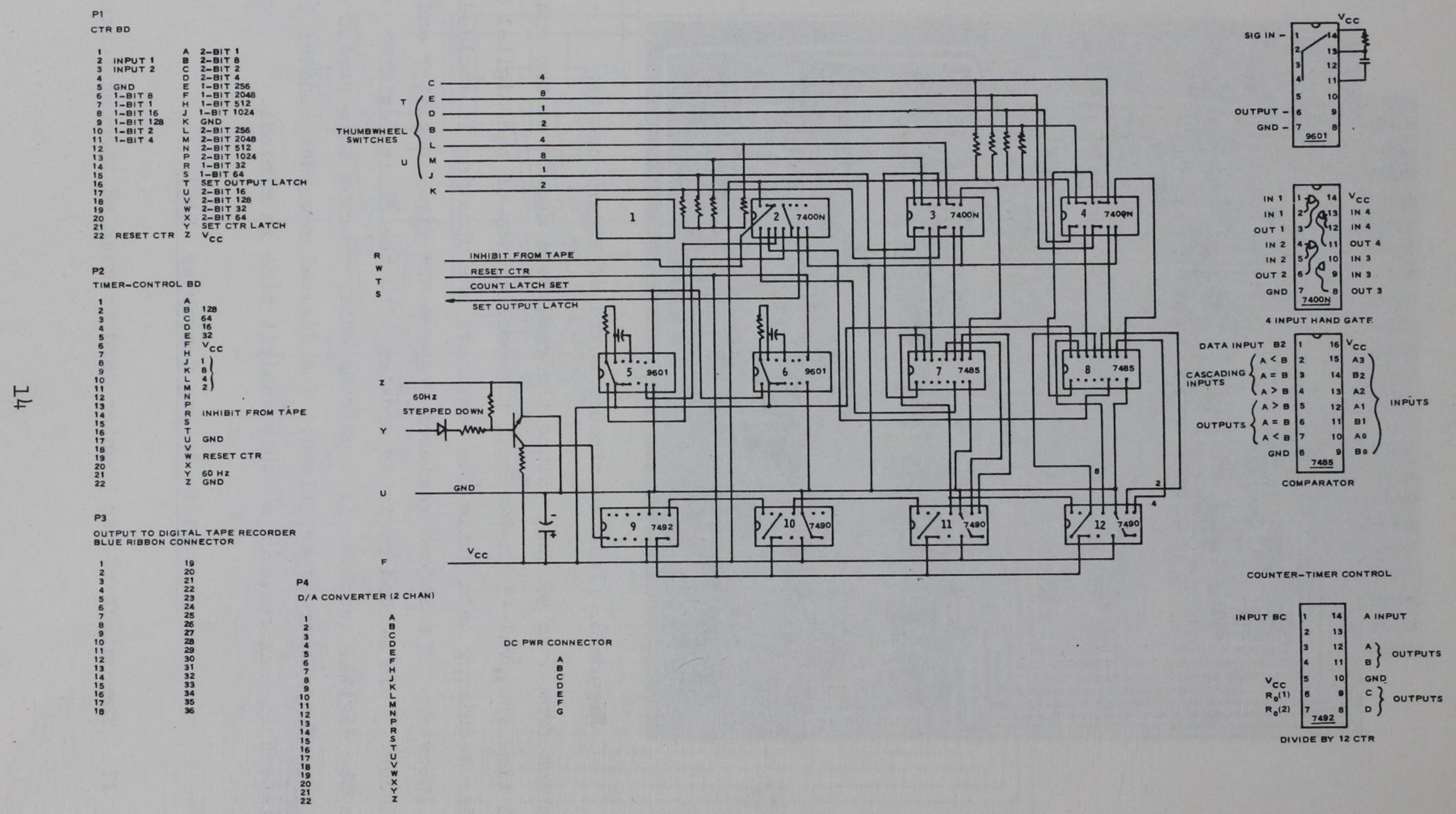

Figure 7. Schematic of controller and timer 


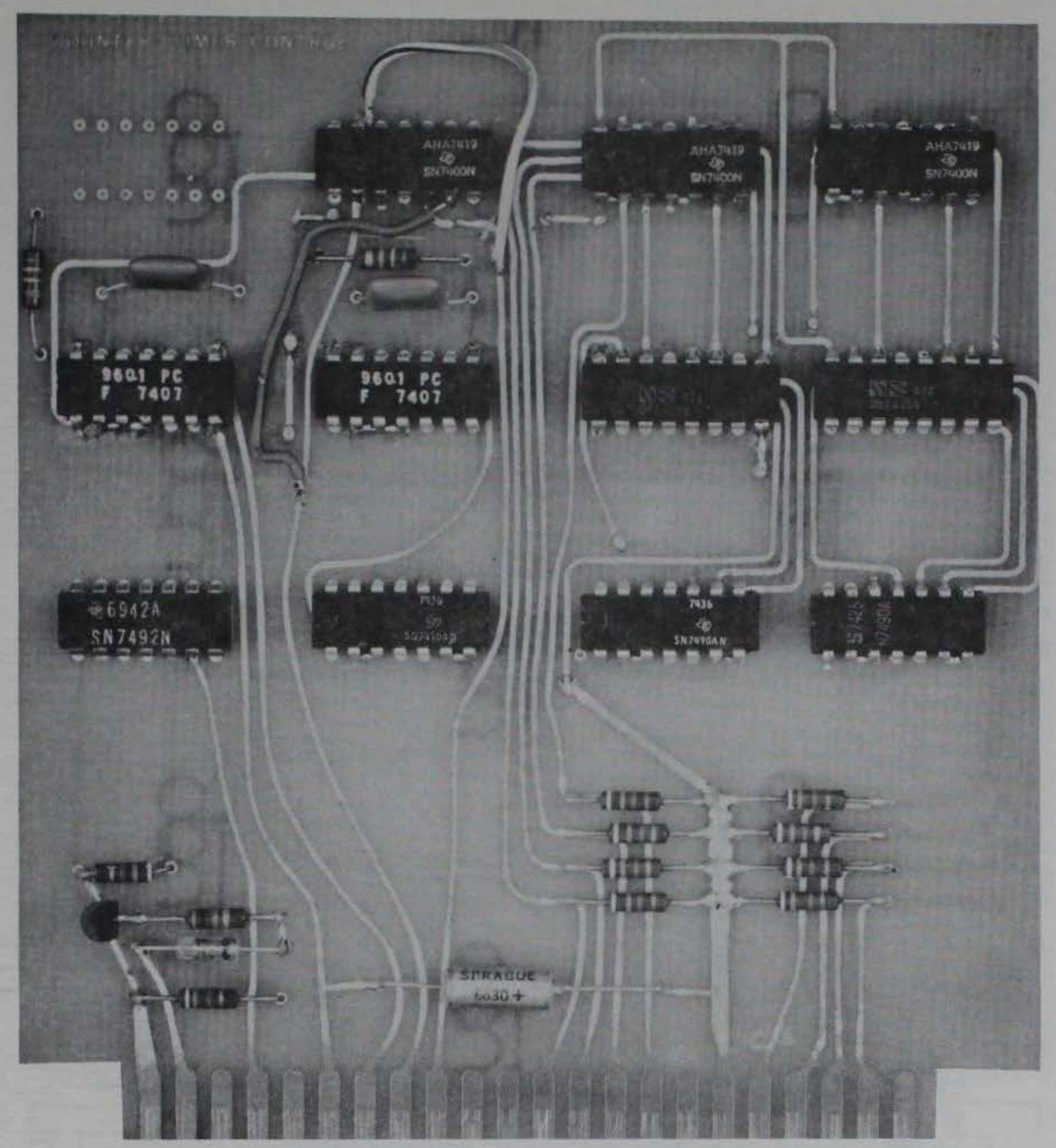

Figure 8. Printed circuit board of controller and timer a commercial DAC manufactured by Analog Devices that has 12-bit resolution and one-half least significant bit accuracy. Detailed specifications are presented in Appendix A. The output of the DAC is coupled to a strip-chart recorder through double-pole, double-throw relay contacts wired in a normal-reverse fashion (Figures 9 and 10). This relay is controlled by the polarity indicator (Figures 11 and 12) which is a set-reset flip-flop used to arrest contact bounce of the polarity switch. The polarity of the analog signal is controlled by this relay, which is controlled by the polarity switch located near the Price meter.

\section{Digital Recorder}

18. The recording system (Figure 1) used in this system is a 


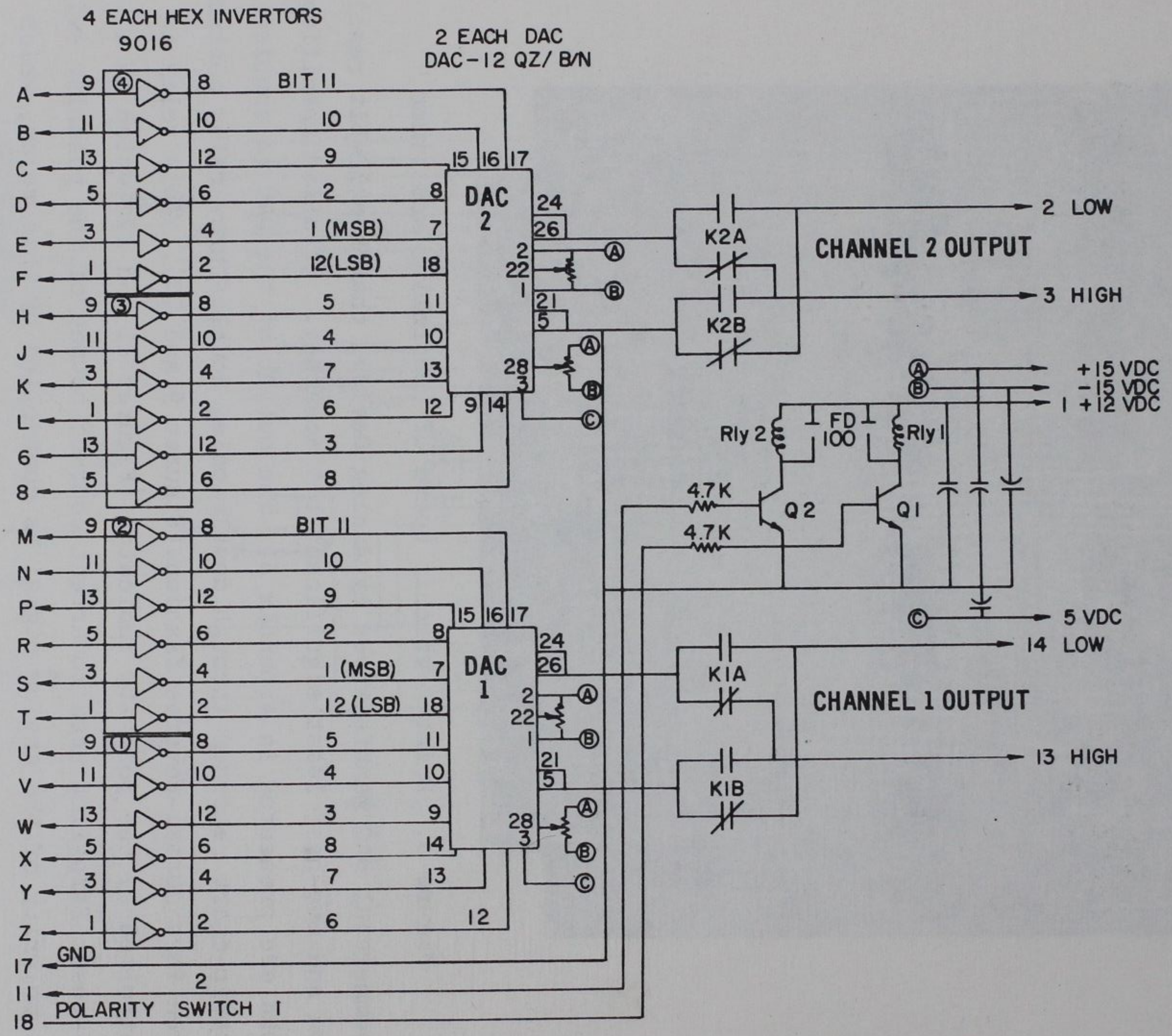

Figure 9. Schematic of digital to analog converter 


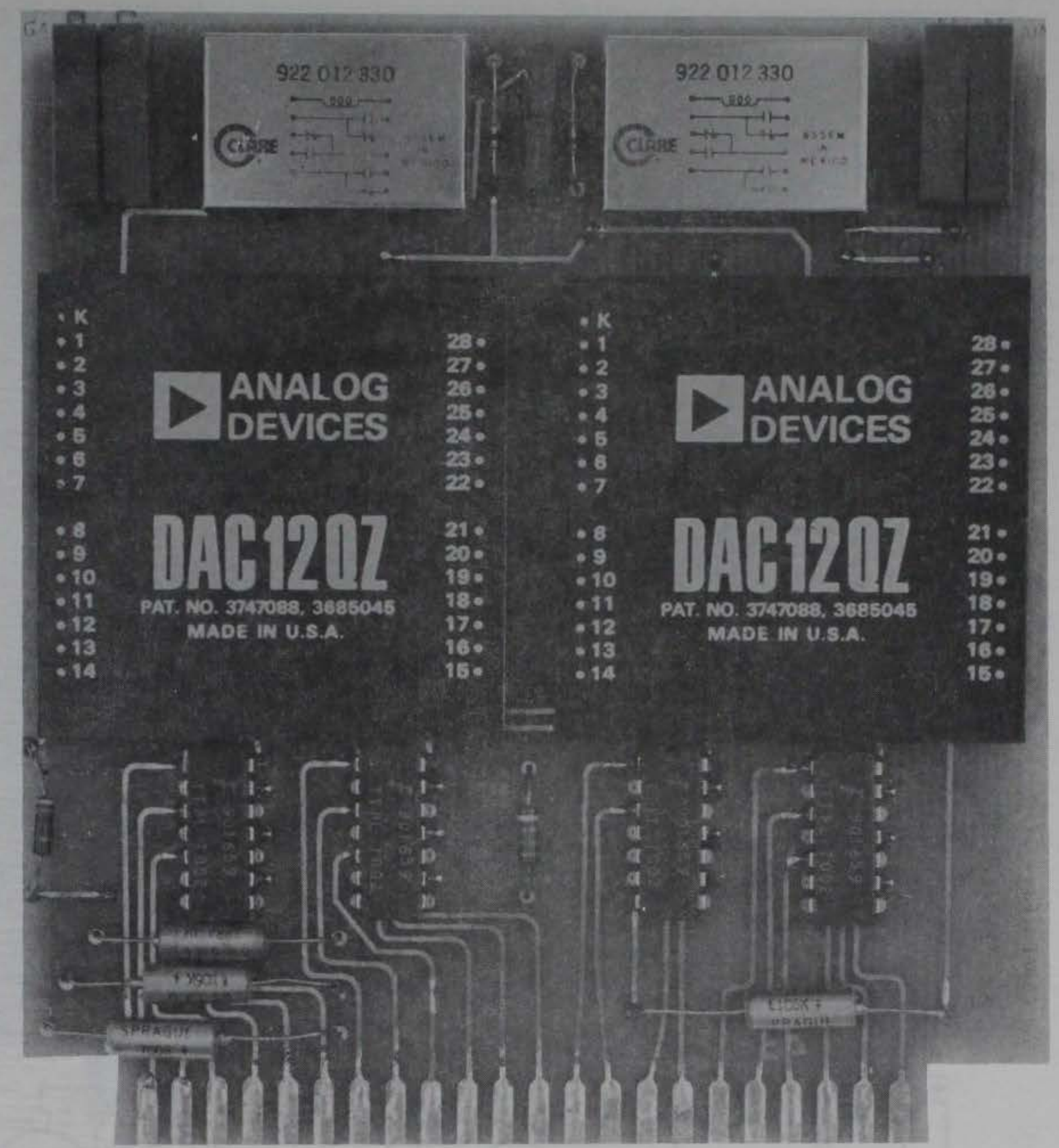

Figure 10. Printed circuit board of digital to analog converter

Datatron Model 1500-131. Detailed specifications of this system are presented in Appendix B. The system is basically a hard-wired, 7-track, 12-bit binary, incremental write recorder capable of writing 1000 characters per second. The system has thumbwheel switches that control the interval between scans (01 sec to $99 \mathrm{hr}$ ), scans per record (000-9999), records per file (00-99), and the last channel (00-31) to be scanned. In addition to these control functions, six uncommitted BCD characters appear in the record header. The multiplexer sequentially scans channels 00 to the last channel selected with the thumbwheel switch (up to 18 channels). The recorder writes a tape in an IBM compatible format as described in PART III of this report. 


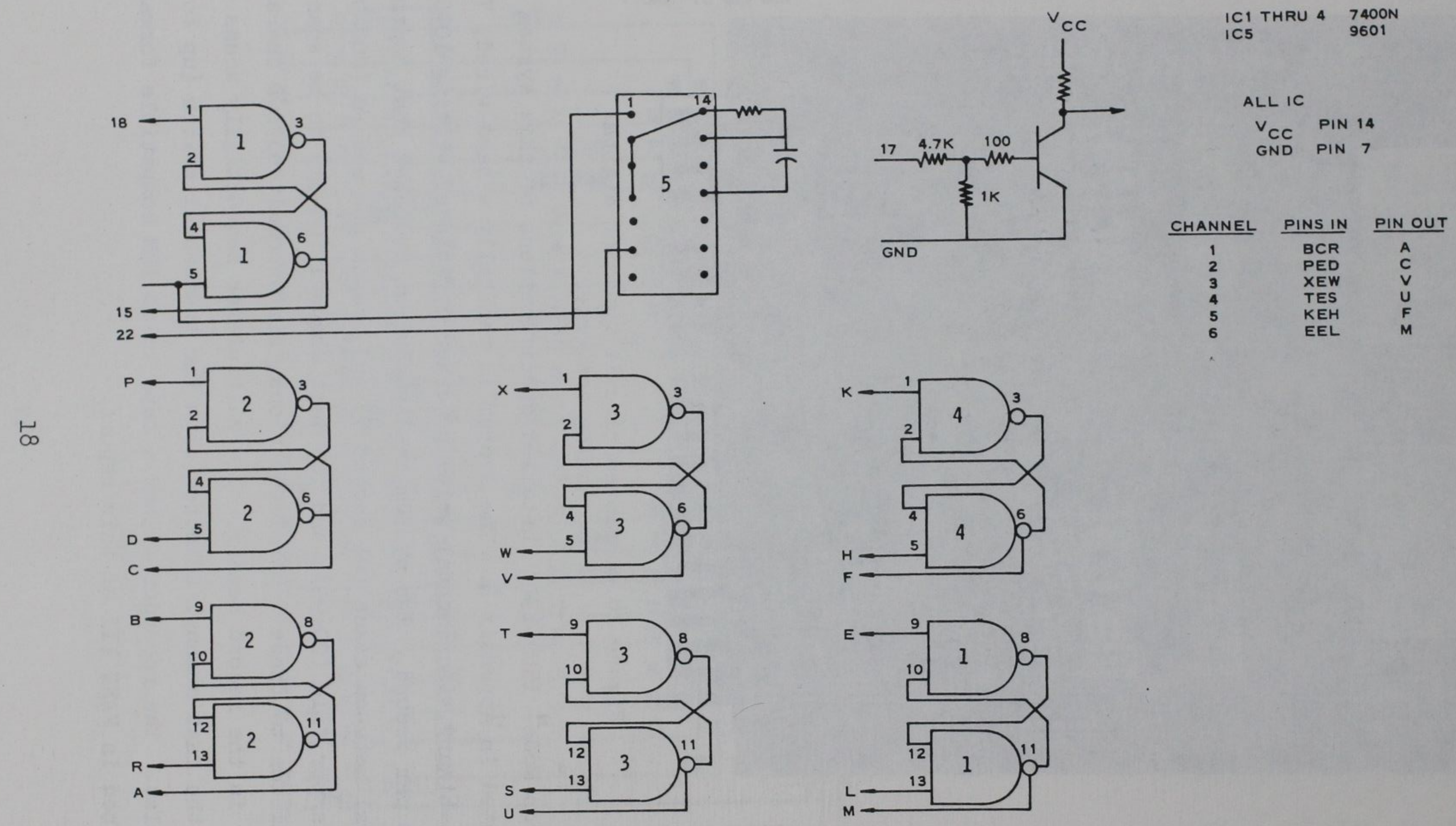

Figure 11. Schematic of polarity indicator 


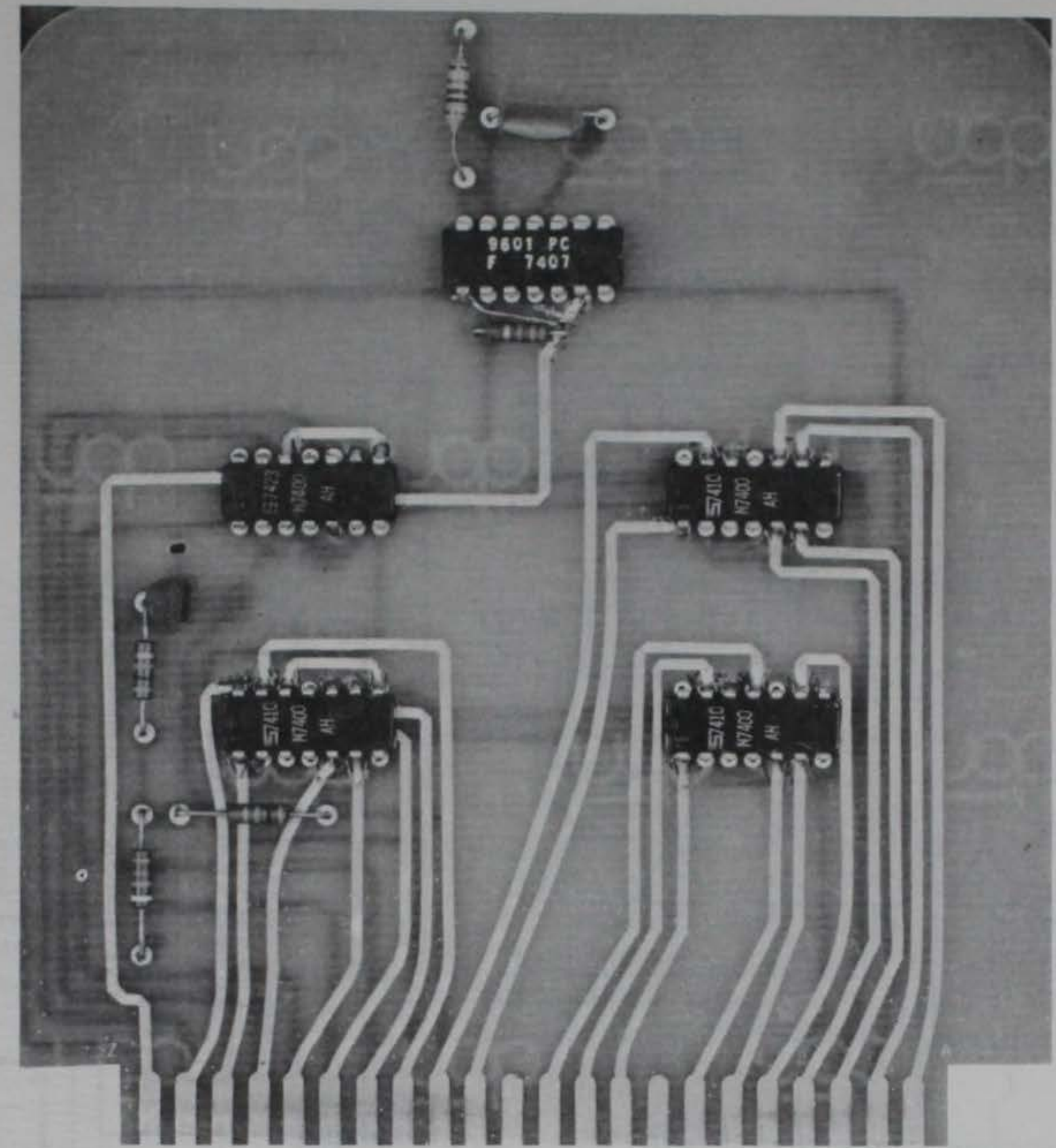

Figure 12. Printed circuit board of polarity indicator

\section{Digital Electronic Clock}

19. The purpose of the digital electronic clock (Figure 13) is to transfer the prototype time from the model clock to the computer compatible magnetic tape so, that tidal elevations and/or other parameters recorded on other recorders can be time-synchronized with the water current measurements. The clock is constructed from integrated circuits, counts pulses from the model clock occurring at 30-min intervals (prototype), and keeps time from 00.0 to $12.0 \mathrm{hr}$ (prototype). The clock also serves as a local readout of prototype time. The coding and the location of the BCD bits are shown in Table 2. 


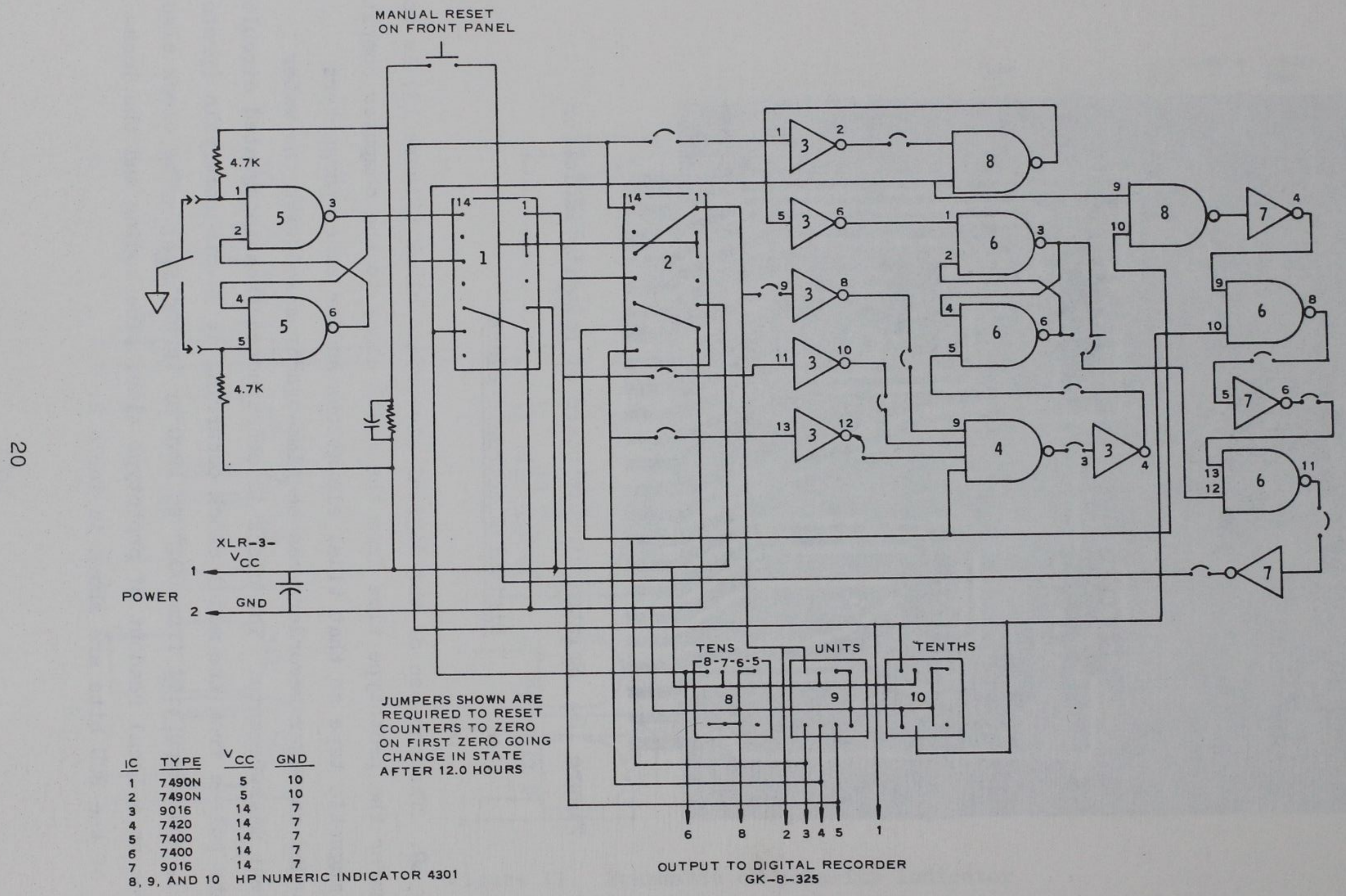

Figure 13. Schematic of digital electronic clock 


\section{Data coupler controls and indicators.*}

Control or Indicator

POWER-ON switch

MODE switch
Function

Applies primary power to Datacoupler

INTVL - Causes selected number of input channels to be scanned repeatedly; interval between each scan is determined by INTERVALOMETER switch positions.

SINGLE - Causes selected number of input channels to be scanned once each time Start/Stop switch is set to START. Settings of INTERVALOMETER switches have no effect.

TEST 1 - Allows operator to record data, one character at a time, to compare contents of Datacoupler with recorded information. One character is recorded when STEP switch is pressed; following character is recorded when switch is released. Binary data contained in Datacoupler is that which appears at inputs when operator steps from header to data portion of format.

TEST 2 - No recording occurs. Datacoupler continuously displays binary data appearing at each input channel. Before input data can be displayed, operator must use STEP pushbutton to advance through header position of format; STEP switch is also used to switch from one input channel to next.

Serves as manual advance control during TEST 1 and TEST 2 modes.

Establish interval between scans during INTVL mode.
INTERVALOMETER

thumbwheel and rotary switches

(Continued)

* From "Model 1500-131 Data Recording Instruction Manual" (unpublished manual), Datatron, Inc., Santa Anna, Calif. 
Control or Indicator

HEADER thumbwheel

RECORDS/FILE

thumbwheel switches

SCANS/RECORD

thumbwheel switches

IAST CHANNEL

thumbwheel switches

CONTROL - START/STOP switch

CONTROL - RESET

pushbutton

TAPE STATUS - RESET

pushbutton

CONTROL - RUN lamp

CONTROL - CONSTANTS

lamp

CONTROL - HEADER

lamp

CONTROL - SCAN lamp

CHANNEL DATA lamps

DATA OUTPUT lamps

CHANNEL NUMBER Lamps

TAPE STATUS - RDY lamp
Function

Establish Constants, Channel, and Year portion of tape header format; see Figure 14, page 29.

Determine number of records contained in each file.

Define number of scans contained in each record.

Regulate length of each scan during INTVL and SINGLE modes; switch settings; determine last input channel to be scanned.

Start position initiates Datacoupler operation during selected mode.

Serves as master reset - clears all Datacoupler logic.

Resets PARITY ERROR lamp.

Lights when Datacoupler is operating.

Lights during "constants" portion of tape header.

Lights during header portion of tape format.

Lights when input data are being scanned.

Each lamp lights when logic "1" appears in appropriate binary input bit position.

Each lamp lights when logic "I" appears in appropriate output bit position. Lamps correspond to tracks on magnetic tape.

Lighted lamps indicate input channel currently being scanned; channel number is indicated in BCD.

Lights when recorder is ready to record data. 
TAPE STATUS - EOT

lamp

TAPE STATUS - BRT

lamp

TAPE STATUS - PARITY ERROR lamp
Lights when end of tape is detected by recorder.

Lights when broken tape is detected by recorder.

Lights when echo parity error is detected by recorder.

21. Operational procedure steps are as follows:

a. The tape is threaded in the tape recorder as shown directly above the power switch.

b. Set the Start/Stop switch on the tape recorder control panel to Stop.

c. Set both the power switches on the current meter counters to the On position.

d. The control readout, located near the middle-right side of the digital tape recorder controller, defines the portion of the format that is presented in the control data readout. All of the machine constants, header, and data channels can be monitored at the control data readout by manually stepping through the format. The format is sequential and does not have a random access capability. All machine constants, header, and data should be checked to ascertain that the system is correctly adjusted.

e. On the tape recorder control panel, set the mode switch to Test 2. This allows the operator to single-step the multiplexer through the whole format to examine all the header and data inputs without recording them on magnetic tape. As the input registers of the digital tape recorder are manually stepped, the channel number readout lamps located on the left side of the front panel indicate the channel addressed. The first channel is 00 , indicated by all lamps being extinguished. This is the first channel monitored when the scan light is illuminated in the control readout. The channel addressed can be determined by adding the numbers associated with the illuminated lamps. Reference to the test specification sheet, supplied by the project engineer, should be made to ensure that proper machine and header constants are entered in the machine.

f. The digital electronic clock is synchronized by resetting to zero when the model clock is at $12.5 \mathrm{hr}$.

g. To check the counters for proper operation, the following adjustments must be performed: 
(1) Connect a square-wave generator to the CAL input on the rear panel of the digital electronic counters of the system. The amplitude of the square wave should be set for +12 volts to simulate an input signal from the Price meter.

(2) Adjust the square-wave generator for the proper period $(T)$ using an electronic counter. Then set the RUN/CAL switch to CAL and observe the binary coded count at the lamps located on the front panel of the controller of the digital tape recorder in the control data readout section. To determine the count, the numbers associated with the illuminated lamps must be added. As an example, with the interval set at one, a 60 pps signal is applied to the system by the square-wave generator. The control data lamps should appear 000000111100 where the "0"s indicate extinguished lamps and the "l"s represent illuminated lamps.

(3) Inputs from the Price meters can be monitored with a scope at the front panel monitor test point. This test point is switchable to each channel. The amplitude of these input should be approximately $\pm 10 \mathrm{v}$.

(4) Set all counter RUN/CAL switches to the RUN position.

h. After all indicators, switch settings, polarities, and amplitudes of calibration are found to be correct, set the totalizing time for the digital counters to the specified time constant (nominally $10 \mathrm{sec}$ ), the mode switch on the digital tape recorder controller to INTERVALOMETER, reset the tape status and control, and set the Start/Stop to start. The above operation will start the recording system and it will automatically record as programmed with the last channel's data appearing in the control data readout between samples. The totalizing time of the counters should be set for one-half the time which the INTERVALOMETER on the digital tape recorder controller is set.

i. The strip chart recorders should be set up as follows:

(1) Chart drive off.

(2) Turn power switch to the On position.

(3) Center white and blue pens with zero control on recorder module.

(4) Set CAL/RUN switch on digital counter to CAL position for desired channel.

(5) Adjust the square-wave generator to desired frequency (pulse rate). 
(6) Set the totalizing interval INTERVALOMETER as specified by the project engineer.

(7) Disconnect the square-wave generator from the counter input, this results in zero input to the strip chart recorder.

(8) Rezero strip chart recorder if necessary.

(9) Connect the square-wave generator to counter input and adjust coarse and fine gain on strip chart for correct amplitude.

(10) Repeat steps 8 and 9 as needed.

(11) Return RUN/CAL switch to RUN and repeat.

(12) When all channels are calibrated for proper deflection, set all polarity switches for proper direction and, if necessary, rezero strip chart pins.

(13) Set specified chart speed and turn on chart drive switch.

(14) After paper begins to move, disconnect square-wave generator and return all RUN/CAL switches to CAL position. This is zero on all channels. Reconnect the square-wave generator; all pens should deflect in the same direction and the same amplitude. This is the strip chart calibration step.

(15) Disconnect the square-wave generator and all pens should return to the original zero line.

(16) This concludes the calibration of the strip chart recorder.

(17) Return all RUN/CAL switches to RUN.

(18) Strip chart is now set up and ready to record data. This concludes the "set up"/calibration procedure, the system should now be prepared to record water current data.

22. The digital recording system has no end of test features which will automatically cease operation of the system; therefore it is necessary to follow certain procedures to ensure that the recording format is not altered. The hydraulic model test shall always be at least one complete file in length. After the number of files for a test is decided, the operation of the system can very easily be halted by placing the Start/Stop switch in the Stop position during the last record of the previous test but prior to the end of file gap generation. The Start time of the test should be noted and the time interval 
corresponding to end of the last record for a particular file of interest can be determined. For example,

$$
\begin{aligned}
\text { Records } / \text { file } & =3 \\
\text { Scans } / \text { Record } & =20 \\
\text { INTERVALOMETER setting (seconds between scans) } & =3
\end{aligned}
$$

therefore, $20 \mathrm{Scans} /$ Record $\times 3 \mathrm{sec} / \mathrm{scan}=6 \mathrm{sec} / \mathrm{rec}$. The end of the second record will have come after $120 \mathrm{sec}$. Shortly thereafter the Start/Stop control switch should be placed in the Stop position in order to cease the test after the recording of this file. This will cause an orderly cessation of the digital recording system in the proper format.

23. The Datatron Model 1500-131 digital recording system can be modified to automatically cease data acquisition at the end of any file. This capability can be obtained by inserting the end of file (EOF) mark pulse into a BCD counter-magnitude comparator-thumbwheel switch combination. The amplitude comparator would be preset with the thumbwheel switch to the next to the last file of interest. After the BCD counter has counted the number of files preset in the comparator, the comparator will generate a pulse which will cause the recording system to enter the Stop mode. This function is done by placing a NAND gate between the Stop switch and the logic elements which it controls. One input to the NAND gate would be the Stop switch and the other input would originate at the magnitude comparator; therefore a change in either input will generate a Stop command that will cease operation at the preselected time. This modification is proposed as a future addition to the present system. 


\section{Outline of Procedures}

24. In this part of the report, the format for the original data tape as created by the recording system (PART II) is described in detail and the procedures of reducing, scaling, editing, and analyzing the original data with sample outputs are presented. The final output of the analyses is interpolated velocity values at selected intervals of an averaged tidal cycle. These data are output on punched cards and are input to an existing tidal data plotting program (WES program number RONEIS/TIDAL). The tidal velocity plots from this existing program are presently accepted as standard form of reduced data for technical reports. Although the existing program with minor modifications could have been incorporated as another activity to the computer analyses presented in this report, a separate computer run of the existing program with card input is chosen. This choice is based on:

a. The familiarity of most model engineers with card input to the existing tidal plotting program.

b. Need to review the velocity data and preliminary plots before final plotting for technical reports.

c. Much of the prototype tidal velocity data is provided to WES on cards and is easily utilized in this form by the existing tidal plotting program.

25. A concise outline of the data analyses and output is as follows :

a. Preprocessor.

(1) Read original velocity data tape.

(2) Demultiplex and scale data.

(3) Store resultant data on permanent data tape.

(4) Output to printer.

b. Data Processor.

(1) Read permanent data tape.

(2) Analyze data and output.

(a) Edit data and print. 
(b) Plot edited data:

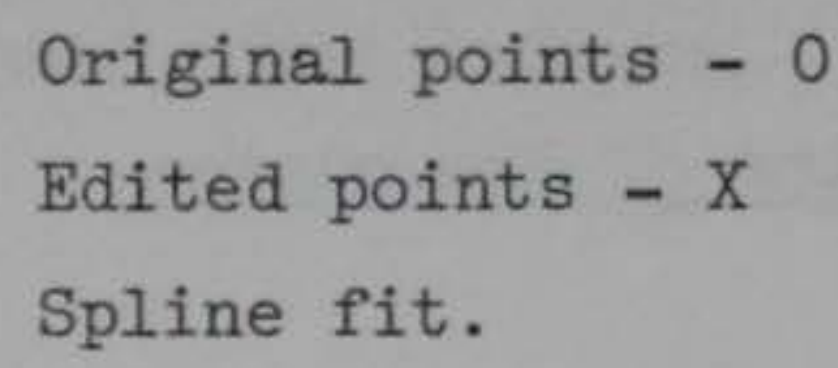

(c) Average two cycles of data and print.

(d) Plot average values and spline fit.

(e) Interpolate $0.5-\mathrm{hr}$ values.

(f) Print interpolated values and punch cards.

\section{Original Tape of Tidal Velocity}

26. Each magnetic tape recorded during a tidal current test contains model time data (first channel plus blank second channel) and model tidal velocity data from a specified number (5) of Price current meters. Each file, which is physically one model run, consists of four records. The first record is a 16-character binary coded decimal (BCD) header of recording equipment constants followed by three records containing data. Each of these one tidal cycle records has an initial 16character $B C D$ header of identification information and 61 scans at 19sec intervals of data from seven measurement channels. The data values are recorded in 12-bit binary data words and are sequentially multiplexed in two characters per data word.

27. The actual number of records per file, scans per record, and channels per scan may vary during system checks and changes in measuring equipment or from model to model. All records are made in ODD parity. The tape format is shown in Table 3, and in greater detail in Figure 14. The characters shown in the bit spaces are for convenient identification only; the actual "markings" are the absence or presence of a magnetized spot.

28. File header (BCD).

a. File header (BCD) has items 1-3 set by manual switches.

(1) Recorder mode code (L), usually "0."

(a) 0 = INTVL - Causes selected number of input channels to be scanned repeatedly; interval between 


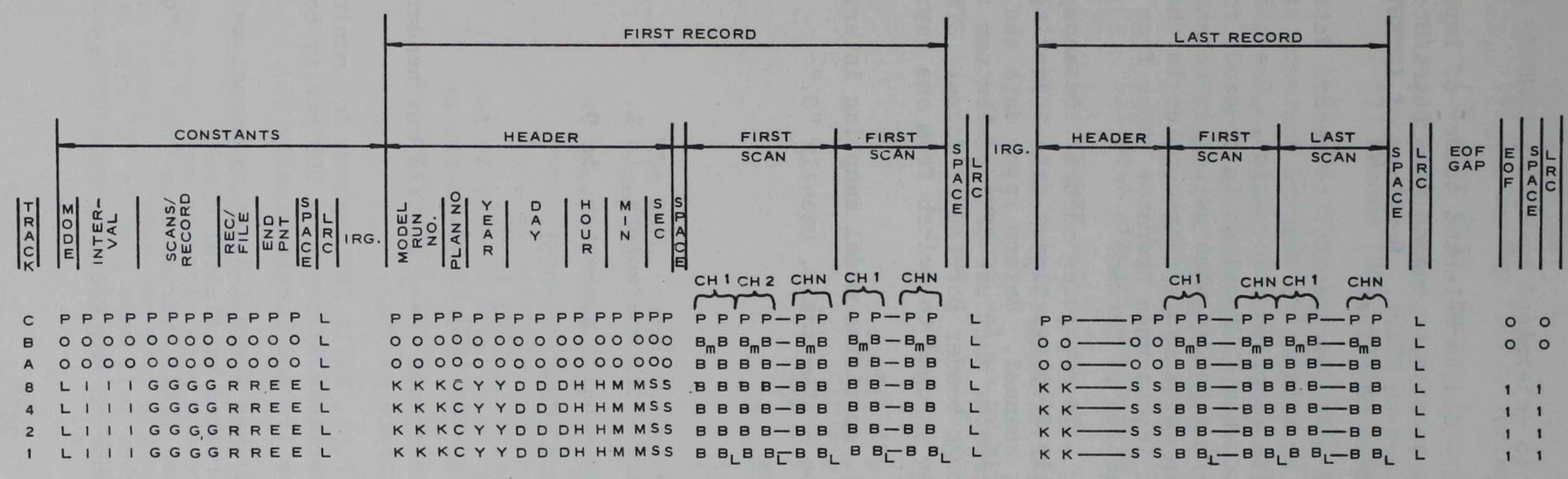

\section{NOTES} 1. ONLY DATA IS IN BINARY FORM (12 BITS):
HEADER, CONSTANT AND TIME CHARACTERS ARE BCD.

2. ODD PARITY IS MAINTAINED BY TRACK C.

3. CONSTANTS APPEAR ONLY AT BEGINNING

4. HEADER APPEARS ONLY AT BEGINNING HEADER APPEARS
OF EACH RECORD.

$\begin{array}{ll}\text { L } & \text { MODE CHARACTER } \\ \text { I INTERVAL CHARACTER } \\ \text { G SCAN/RECORD } \\ \text { R RECORDS/FILE } \\ \text { E LAST CHANNEL } \\ \text { K MODEL RUN NO. } \\ \text { C MODEL PLAN NO. } \\ \text { Y YEAR (HEADER SWITCHES) } \\ \text { D DAYOF, YEAR } \\ \text { H HOUR }\end{array}$

LEGEND

$\begin{array}{ll}M & \text { MINUTE } \\ S & \text { SECOND } \\ B_{m} & \text { MOST SIGNIFICANT BIT } \\ B & \text { BINARY BIT } \\ \text { BL LEAST SIGNIFICANT BIT } \\ \text { SP } & \text { B CHARACTER SPACES } 0.072 " \\ \text { LRC } & \text { LONGITUDINAL REDUNDANCY CHECK } \\ \text { IRG } & \text { INTERRECORD GAP } 0.75 " \\ \text { EOF } & \text { END OF FILE MARK } \\ P & \text { PARITY }\end{array}$

Figure 14. Magnetic tape data format 
each scan is determined by INTERVALOMETER switch positions.

(b) 1 = SINGLE - Causes selected number of input channels to be scanned once each time Start/Stop switch is set to Start. Settings of INTERVALOMETER switches have no effect.

(c) 2 = TEST 1 - Allows operator to record data, one character at a time, to compare contents of Datacoupler with recorded information. One character is recorded when STEP switch is pressed; following character is recorded when switch is released. Binary data contained in Datacoupler is that which appears at inputs when operator steps from header to data portion of format.

(d) 3 = TEST 2 - No recording occurs. Datacoupler continuously displays binary data appearing at each input channel. Before input data can be displayed, operator must use STEP pushbutton to advance through header portion of format; STEP switch also is used to switch from one input channel to next.

(2) Interval (III), specifies model sampling interval.

(a) First space - time scale, usually "0."

$0=$ seconds

1 = minutes

2 = hours

(b) Second space - ten characters, is 1 .

(c) Third space - units character, is 9.

(3) Scans per record (GGGG) is 0061.

(4) Data records per file (RR) is 02.

(5) Last channel in scan (EE) is 06.

(6) Three character spaces (---) to fill out header character to a multiple of four.

(7) Parity check $(P, L)$, built into system for monitoring equipment performance by checking ODD parity both across the tape (P) and longitudinally (L).

b. Record header (BDC) has items 1-3 set by manual switches and items d-g controlled by digital clock.

(1) Model run number (KKK), varies from "001" to "999."

(2) Model plan number (c), base plan is "0" with other model plans numbered sequentially from " 1 " to "9." 
(3) Year (YY).

(4) Julian Day (DDD), varies from "001" to "365."

(5) Hour ( $\mathrm{HH})$, varies from "00" to "23."

(6) Minute (MM), varies from "00" to "59."

(7) Second (SS), varies from "00" to "59."

(8) One space $(-)$, to fill out header character spaces to a multiple of four.

c. Data scans (12-bit binary) are composed of velocity values from each channel recorded sequentially usually with "channel $\mathrm{n}$ " equal "channel 7." (Note that data channels 1-7 are recorded in sequence on tape channels 00-06.)

(1) Most significant bit $\left(B_{M}\right)$.

(2) Binary bit (B).

(3) Least significant bit $\left(B_{L}\right)$.

(4) Equivalent values of bits representing decimal values of instrument output counts:

$$
\begin{array}{rlrl}
2048 & =\mathrm{B}_{M} & \mathrm{~B} & =32 \\
1024 & =\mathrm{B} & \mathrm{B} & =16 \\
512 & =\mathrm{B} & \mathrm{B} & =8 \\
256 & =\mathrm{B} & \mathrm{B} & =4 \\
128 & =\mathrm{B} & \mathrm{B} & =2 \\
64 & =\mathrm{B} & \mathrm{B}_{\mathrm{L}} & =1
\end{array}
$$

The total count for each data value can vary between 0 and 4095.

(5) The last data scan of each record is followed by three character spaces (---) and a longitudinal parity check (L), as described above for the file header.

d. End of file is identified by a 3.75-in. end-of-file gap, an end-of-file mark ( 1 ), three character spaces (---), and a longitudinal parity check (L).

\section{Preprocessor}

29. The preprocessor computer program is a multipurpose program designed to read from magnetic tape and convert to G635 system binary data whose number of bytes per word differs from 6635 computer. In addition, the preprocessor scales and outputs the resultant data. For the 
tidal model option, the preprocessor reads the original data tape and uses card input to control data manipulation and to select options, then it demultiplexes the data, scales to prototype units, and stores resultant data in a file on a permanent data tape for use by the data processor. These data also are output to the printer.

\section{Procedures for the processor}

30. The preprocessor reads the data tape, makes use of card input to ensure that the correct data are read, demultiplexes the data, scales the data to engineering units, stores the data on disc, edits the data to remove obvious data errors, and finally stores the resultant data on a disc or tape file for later use by a data processor. The preprocessor consists of the following routines:

\section{MAIN - Driver routine; reads card input and exercises the various options as specified.}

Subroutines

TRANSLATR - Breaks out the packed data words into machine words for natural binary, two's-complement binary n-bit data ( $n \leq 36)$, or special binary format for Price current meters.

FHDRCK - Checks the data read from the file header against card input.

RHDRCK - Checks the data read from the record header to ascertain the time and channels calibrated; also has option to check the time against the requested Start time or check the model test number against the requested model test number.

BRMTREDT - Checks the barometric pressure for the record and returns the average barometric pressure for the record to be used in scaling.

SCALDATA - Scales the wave data, velocity data, and temperature data according to input parameters:

(1) Equation for submerged pressure transducers

$$
\mathrm{n}=\mathrm{A}^{*} \mathrm{~K}+\mathrm{B}
$$

$A=$ Linear scale factor (input AARRAY)

$B=$ BARRAY + REL-APAVG where BARRAY is input intercept ARRAY and REL is input relative elevation ARRAY. 
(2)

Equation for all other sensors

$$
\mathrm{n}=\mathrm{A} * \mathrm{~K}+\mathrm{B}
$$

$$
\begin{aligned}
A= & \text { As above } \\
B= & \text { BARRAY + OFFSET where BARRAY is same as above } \\
& \text { and OFFSET is input OFFSET for a desired trans- } \\
& \text { lation of data. }
\end{aligned}
$$

STORDATA - Stores the data for future use in one of the following manners:

(1) Record by record as read and scaled to disc,

(2) After editing calls DSKTAP to store data on tape, or

(3) Record by record as read and scaled to tape.

EDITDATA - After all records have been read and stored on disc, edit data is called to edit out any spikes and to reconstruct short sequences of lost data using subroutine datafill.

DSKTAP - Transfers data from disc to tape and creates a tape file header.

STATS - Used to calculate mean and variance of a data set.

DATAFILL - Reconstructs missing data according to NEDIT option (1-tide only, 2-tide and waves) by performing a leastsquares linear fit of the tide and superimposing the residual wave data from before and after the data gap.

LSQFIT - Least-squares polynomial fitting routine.

SMOOTH - A "feathering-in" procedure for reconstructed data sequences.

PRICE - Special subroutine for converting data from model Price velocity meters.

MTIME - Special subroutine for converting time on model to machine data.

\section{Preprocessor input}

31. The card inputs including formats and parameter definitions for the preprocessor program are presented below.

CARD $1 \mathrm{NCH}$ - \# of channels recorded

(16I5) NSOR - \# of scans per record

NRPF - \# of data records per file

NNBWPFH - \# of n-bit data words per file header 
NFCK - \# of checks to be made on file header info NNBWPRH - \# of n-bit data words per record header NRCK - \# of checks to be made on record header info NCHU - \# of channels of data actually to be preprocessed NEDIT - Editing option: 0-no editing; 1-tide only; 2-tide and waves

NSAV - Data save option: 0-no save; 1-save edited or original data.

NREC - 3 of records actually to be preprocessed per file NBPDW - I (\# of bits per data word): or $+=$ Special format keyed on NBAGTP $+=$ Natural binary; - complemented

IST $\varnothing 1$ - $\varnothing$ if counters start at $\emptyset 1,1$ if counters start at 1

CARD 2 IDEVIN - Logical device \# of input

(16I5) IDEVOT - Logical device \# of output

ISAV - Logical device \# of save file

ISCR - Logical device \# of scratch file

CARD $3(\operatorname{ISTIM}(I), I=1,5)$ - Requested start time (yr day $\mathrm{hr}$ min sec) or flag for tidal model test consisting of (neg. starting run no., final run no., blank, blank, blank).

MXNBP - Maximum number of bad data points acceptable for correction

ICKTIM - $=\varnothing$, if time is used to key on $\neq$, if time is merely information

$\operatorname{CARD}(S) 4$ (ISC(I),I=1,NCG) - I,DO;0, Do not use data for channel I (16I5)

CARD(S) 5 (NGAGTYP(I), I=I,NCH) - 0, designates channel recorded no data

1, submerged pressure transducer

2, surface-piercing resistance gage

3, barometer

4, velocity (Price meter)

5, temperature

6, special time

7, Marsh-McBirney velocity

***NOTE*** To mix complemented and any other code is undefined special 
format data, set NBPDW + and prefix the codes here by - so that a complementing routine will be called.

CARD(S) 6 (AARRAY(I) I=1,NCH) - Linear scaling factor for each chan$(8 \mathrm{fl} 0.5)$ nel I for converting binary counts to engineering units $(=0.1$ for NGAGTYP = 6)

$\operatorname{CARD}(\mathrm{S}) 7$ (BARRAY(I), I = I, NCH) - Intercept for each channel I corre$(8 \mathrm{fl0.5)}$ sponding to zero binary counts $(=0.0$ for NGAGTYP $=6$ )

$\operatorname{CARD}(S) 8$ (REL(I), I=l, NCH) - Relative elevation of each channel I $(8 \mathrm{f} 10.5)$ (Referenced to a known datum plane) $(=0.0$ for NGAGTYP $=6)$

$\operatorname{CARD}(\mathrm{S}) 9$ (OFFSET(I), I=1,NCH) - Offset value for each channel $I$ as $(8 \mathrm{fl0.5)}$ applicable $(=0.0$ for NGAGTYP $=6)$

$\operatorname{CARD}(\mathrm{S}) 10$ (IFCK(I), I=l,NFCK) - Parameter description for each file header check

CKNCHB - \# of channels

CKNSPR - \# of scans per record

CKNRPF - \# of data records per file

CKDELT - Integer sampling interval

CKNCBB - No check made

CKSPPL - Special check with ICKF(I)

$\operatorname{CARD}(\mathrm{S})$ IOA (ICKF(I), I=l, NFCK) - Integer data values to check for (16I5) CKSPCL parameter

CARD(S) 11 (IRCK(I),I=l,NRCK) - Parameter description for each record $(13 \mathrm{~A} 6, \mathrm{ZX})$ header check

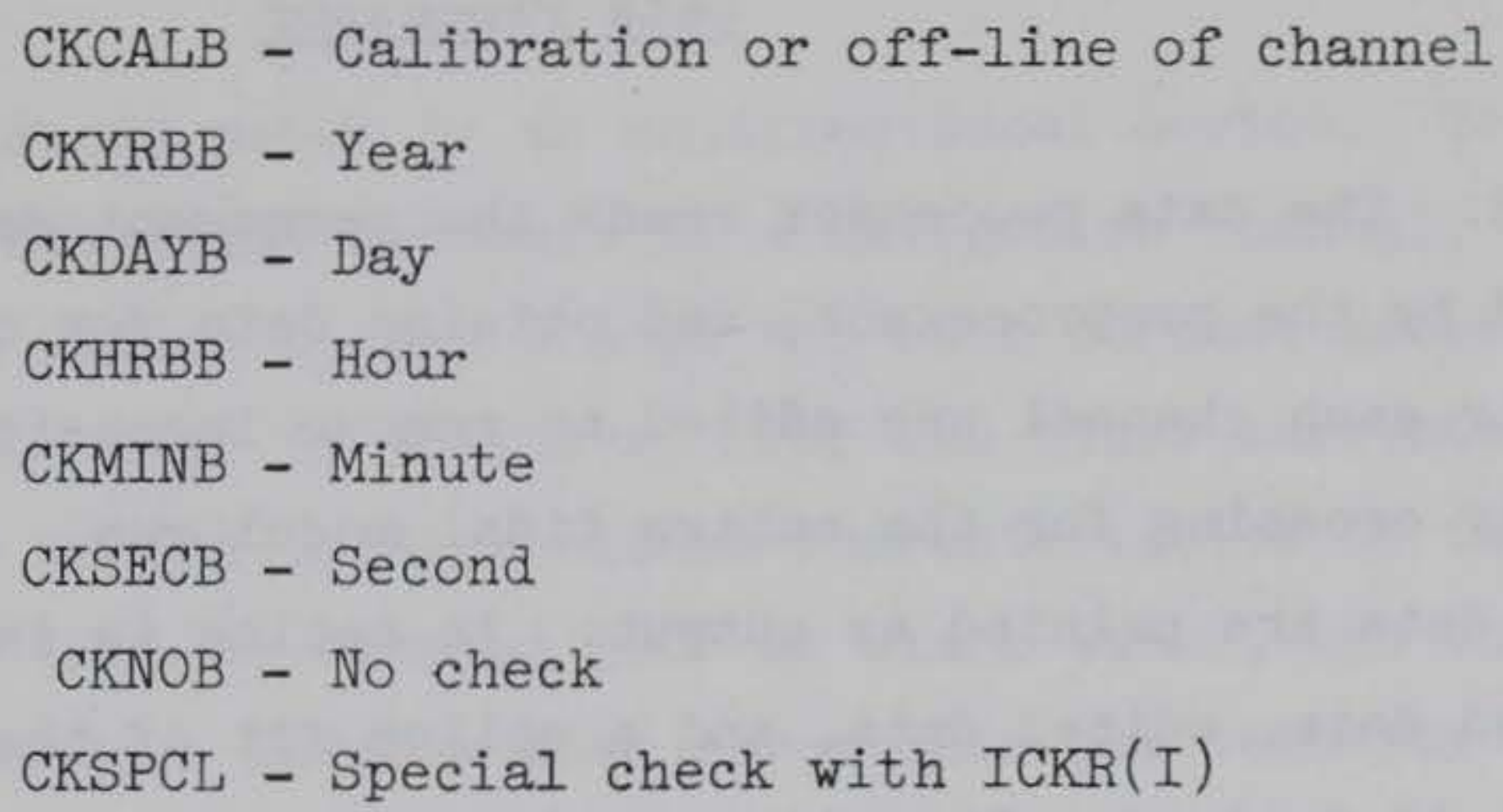


CARD 12 ( $\operatorname{LABGAG}(I), I=1, N C H)$ - Gage labels

(20A4)

CARD 13 DELT - Sampling interval (seconds)

(8f10.5) DEVMAX - Maximum acceptable first-difference criterion

CARD 14 FHFMT - Format according to which file header info is decoded (A80)

CARD 15 RHFMT - Format according to which record header info is decoded (A80)

CARD 16 MDLTTL - Model title

(A50)

\section{Preprocessor outputs}

32. The outputs of the preprocessors are a data file on a specified permanent data tape, printed model data, and other pertinent information. The magnetic tape file consists of a BCD file header and $N$ records of demultiplexed, scaled binary data. A schematic of the tape format for this permanent data tape is Table 4 . In addition to the permanent data tape, the printed output of model information and data values are scaled velocity values ( $f p s$ ) in prototype units. These scaled values depend on each Price meter calibration coefficient (linear scaling factors and intercepts) used to scale the binary count data of each channel. An example of model parameter information and prototype velocity data for one channel may be found in Appendix C.

\section{Data Processor}

33. The data processor reads the permanent data tape, which is created by the preprocessor, and obtains data for one channel at a time. Data for each channel are edited to remove inconsistencies at each zero velocity crossing for the entire tidal model run. Both unedited and edited data are printed as output. An option is included to plot the unedited data, edited data, and a spline fit of the edited data for each channel if desired. Starting at prototype time zero during the first cycle of the model, the following two tidal velocity cycles are averaged. The resulting cycle of averaged data is printed as output and also may 
be plotted with a spline fit if desired. Finally, data values are interpolated using a spline routine at half-hour intervals from zero to $12 \mathrm{hr}$. These interpolated data are printed as output and also punched on cards in a format compatible as input to the tidal data plotting program (WES program number ROHEIS/TIDAL) by L. L. Daggett.

\section{Data processor input}

34. Cards inputs including formats and parameter definitions for the processor program are presented below. CARD $1 \operatorname{IOPT}(I), I=, N C H$ - Options for each channel (16I5)

$$
\begin{aligned}
& 0 \text { - Channel was not used } \\
& 1 \text { - Channel used but no plots desired } \\
& 2 \text { - Plot only unaveraged data } \\
& 3 \text { - Plot only averaged data } \\
& 4 \text { - Plot both unaveraged and averaged data }
\end{aligned}
$$

CARD 2 JFLAG - $\frac{\text { Negative }}{\text { analyses }}$ number of model run to begin tidal velocity (16I5)

$$
\text { JFND - Number of final run to be analyzed. }
$$

NOTE - This card can be the same card used for card \#3 of input to the preprocessor. If computer run is independent of preprocessor, run number must be pos

CARD 3 MDLTTL - Model title

(A50) Centered in field

\section{Data processor edit}

35. The Price current meter is an unidirectional device. To distinguish flood and ebb tidal currents in a navigation channel, the recording system has a switch to set a sign for each current meter. For flood tidal currents the sign is positive. For ebb tidal currents the sign is negative. Due to the unidirectional characteristics of the Price meter, the meter must be rotated $180^{\circ}$ at slack water, and the sign bit changed. This procedure induces some error into the velocity data near slack water. This error is associated with the time chosen by the model operator to rotate the current meters. Since slack water does not occur simultaneously at all velocity stations in the tide model, the 
correct time to rotate each current meter is difficult to determine. Estimates of this time for each velocity station will be in error. Thus, magnitude and direction errors will exist near slack water. The data processor edit routine checks velocity data for zero values and sign changes. When either of these occurs, the routine takes the previous data point and assumes it to be good. The routine then skips a predetermined number of points and assumes that the resultant point is also good. Using these two good points, the equation for a straight line through these two points is determined. Values to replace bad data values are calculated using this equation. The number of points skipped at slack water is determined by MXNBP (maximum number of bad points) in the first parameter statement in the data processor. The actual number of points skipped and replaced by calculated values is one less than MXINBP. Data processor output

36. Printed output for the data processor consists of velocity and model time information with unedited, edited, averaged, and interpolated data. This information is printed in the same format as in the preprocessor output and also includes linear scaling factors and intercepts.

37. Data from channel $I$ are the model clock times not edited. Data for all other channels are edited at each zero crossing by inserting a straight line to replace bad data points. Polynomial coefficients of the straight line, $A X+B$, for each zero crossing are printed where $X$ is the sequence number of the bad point. Unedited and edited data values are printed for each cycle. If desired, a plot of this information may be produced for each channel. Plotted parts are keyed as follows:

$$
\begin{aligned}
& \text { Unedited data points - (I) } \\
& \text { Edited data points - X } \\
& \text { Spline fit of data }
\end{aligned}
$$

Examples of printed output and plots are presented in Appendix D.

38. Average data values obtained by averaging two cycles starting with the scan number corresponding to the first zero reading on the model clock are calculated and printed by the processor. This output includes model clock time, prototype time calculated from scan number, and averaged data values. The optional plot of this information shows 
averaged values noted by $X$ and a spline fit through these points. Examples of this output are presented in Appendix D. 
39. Previous procedures of collecting model velocity data with miniature Price meters have been improved and updated by:

a. Using digital counters to accumulate over a selectable sampling interval the number of electric pulses received through fiber optic techniques from the rotation of the cups of the Price meter.

b. Implementing a portable digital recorder to record the above digital output on 7-track magnetic tape.

c. Using a digital to analog converter to provide analog output for visual inspection of velocity data by model operator.

d. Developing computer programs for reducing, editing, and analyzing the recorded velocity data.

At the option of the user, the final form of the analyzed data can be output on cards for compatibility with past procedures (WES Program No. ROHEIS/TIDAL) of preparing tidal velocity plots for technical reports.

40. Efforts described in this report have provided tidal inlet model studies of WDD with an automated procedure of collecting, editing, analyzing, and formally documenting tidal velocity data. This procedure does not require the direct use of an ADACS, and the sensors and recording system are sufficiently portable to be moved from one model to another. Although this system of collecting tidal velocity is automated, the limitations (e.g. velocity resolution, high threshold velocity, nonlinear response at low velocities, and unidirectional response) of the Price meter are still present and must be carefully considered during data interpretation. Improvements in model transducers for monitoring velocities are certainly desirable, and other methods of measuring velocities in physical models must be pursued fully and evaluated in the near future to keep pace with other automated advances in hydraulic modeling techniques. 


\section{REFERENCES}

1. Daggett, Larry, "Automation of Control, Data Acquisition and Data Processing for the New York Harbor Model," Paper presented ASCE Hydraulics Specialty Conference, Aug 1971, Iowa City, Iowa.

2. Durham, D. L., Greer, H. C. III, and Whalin, R. W., "Automated Control, Data Acquisition, and Analyses for Hydraulic Models of Tidal Inlets," Report No. 76-3, Sep 1976, Proceedings 1976 Army Numerical Analysis Conference, U. S. Army Research Office.

3. Durham, D. L. and Greer, H. C. III, "Automated Data Acquisition and Control Systems for Hydraulic Wave Models," Paper presented at 1975 Army Numerical Analysis Conference, Feb 1975, St. Louis, Mo.

4. Whalin, R. W. et al., "A Case History of Los Angeles-Long Beach Harbors," ASCE Proc. of International Symposium on Ocean Wave Measurement and Analysis, Vol 1, Sep 1974.

5. Outlaw, D. G. et al., "Los Angeles and Long Beach Harbors Model Study; Model Design," Technical Report H-75-4, Report 4, Feb 1977, U. S. Army Engineer Waterways Experiment Station, CE, Vicksburg, Miss.

6. Sager, R. A. and Holyfield, N. W., "Masonboro Inlet, North Carolina: Movable-Bed Hydraulic Model Study; Effects of Temperature and Experimental Procedures," Miscellaneous Paper H-75-10, Dec 1975, U. S. Army Engineer Waterways Experiment Station, CE, Vicksburg, Miss.

7. Herrmann, F. A., Jr., and Tallant, I. C., "Plans for Reduction of Shoaling in Brunswick Harbor and Jekyll Creek, Georgia; Hydraulic Model Investigation," Technical Report H-72-5, Sep 1972, U. S. Army Engineer Waterways Experiment Station, CE, Vicksburg, Miss. 
Table 1

\section{Counter Binary Code for Price Meter}

\begin{tabular}{lcllllllllllll}
\hline Truth Table & MSB & & & & & & & LSB \\
+ Full scale (flood) & 1 & 1 & 1 & 1 & 1 & 1 & 1 & 1 & 1 & 1 & 1 & 1 \\
+ Full scale -1 & 1 & 1 & 1 & 1 & 1 & 1 & 1 & 1 & 1 & 1 & 1 & 0 \\
Zero +1 & 1 & 0 & 0 & 0 & 0 & 0 & 0 & 0 & 0 & 0 & 0 & 1 \\
Zero & 0 & 0 & 0 & 0 & 0 & 0 & 0 & 0 & 0 & 0 & 0 & 0 \\
Zero -1 & 0 & 0 & 0 & 0 & 0 & 0 & 0 & 0 & 0 & 0 & 0 & 1 \\
- Full scale -1 & 0 & 1 & 1 & 1 & 1 & 1 & 1 & 1 & 1 & 1 & 1 & 0 \\
- Full scale (ebb) & 0 & 1 & 1 & 1 & 1 & 1 & 1 & 1 & 1 & 1 & 1 & 1
\end{tabular}


Table 2

Electronic Model Clock Binary Codes

for Digital Recording

\begin{tabular}{llc}
\hline \multicolumn{3}{c}{ Location on Digital Recorder } \\
\cline { 2 - 3 } 12 & Hours & BCD Weights \\
11 & Tens & 1 \\
10 & Units & 8 \\
9 & Units & 4 \\
8 & Units & 2 \\
7 & Units & 1 \\
6 & Always & 0 \\
5 & Always & 0 \\
4 & Always & 0 \\
3 & Fraction & 8 \\
2 & Fraction & 4 \\
1 & Fraction & 1
\end{tabular}

Truth Table, BCD Weights

\begin{tabular}{|c|c|c|c|c|c|c|c|c|c|}
\hline \multirow[b]{2}{*}{ Count } & \multicolumn{4}{|c|}{ Fraction } & \multicolumn{4}{|c|}{ Units } & \multirow{2}{*}{$\frac{\text { Tens }}{12}$} \\
\hline & 1 & 2 & 3 & 4 & 8 & 9 & 10 & 11 & \\
\hline 0 & 0 & 0 & 0 & 0 & 0 & 0 & 0 & 0 & 0 \\
\hline 1 & 1 & 0 & 0 & 0 & 1 & 0 & 0 & 0 & 1 \\
\hline 2 & 0 & 1 & 0 & 0 & 0 & 1 & 0 & 0 & \\
\hline 3 & 1 & 1 & 0 & 0 & 1 & 1 & 0 & 0 & \\
\hline 4 & 0 & 0 & 1 & 0 & 0 & 0 & 1 & 0 & \\
\hline 5 & 1 & 0 & 1 & 0 & 1 & 0 & 1 & 0 & \\
\hline 6 & 0 & 1 & 1 & 0 & 0 & 1 & 1 & 0 & \\
\hline 7 & 1 & 1 & 1 & 0 & 1 & 1 & 1 & 0 & \\
\hline 8 & 0 & 0 & 0 & 1 & 0 & 0 & 0 & 1 & \\
\hline 9 & 1 & 0 & 0 & 1 & 1 & 0 & 0 & 1 & \\
\hline
\end{tabular}


Table 3

Original Data Tape Format

Record 1

- File Header:

1. Recorder mode code.

2. Sampling interval.

3. \# of scans per record. (NSCANS)

4. \# of records per file. (NRECS)

5. Last channel in scan.

6. Three character spaces.

7. Parity check.

Record 2 - NRECS - Data records

1. Record header.

a. Run number.

b. Model Plan number.

c. Year.

d. Julian day.

e. Hour.

f. Minute.

g. Second.

h. Space.

2. Data Scans (1-NSCANS)

a. First scan for first channel.

b. First scan for last channel.

c. Last scan for first channel.

d. Last scan for last channel.

End of File 
Table 4

Preprocessor Output: Permanent Data Format

Record 1 - File Header:

1. Run number (IRUN).

2. Plan number (IPLAN).

3. Sampling interval (DELT).

4. \# of scans per cycle (NSPR).

5. \# of records preprocessed per file (NREC).

6. Starting time of model run (year, day, hour, minute, second).

7. ISC(I), I=I, NCH from input card \#4.

8. Scale factor for each channel.

9. Intercept for each channel.

Records 2-N - Demultiplexed data with data values per record and records per channel.

- End of file. 
APPENDIX A: DIGITAL TO ANALOG CONVERTER SPECIFICATIONS 


\section{Low Cost General Purpose Digital to Analog Converter}

\section{DAC-120Z}

\section{FEATURES}

Low Cost: $\$ 47(100+)$

12 Bit Resolution

$1 / 2$ LSB Linearity

$\pm 30 \mathrm{ppm} /{ }^{\circ} \mathrm{C}$ TC

20ppm/\% Power Supply Rejection

Programmable Output Ranges

Small Size $-2^{\prime \prime} \times 2^{\prime \prime} \times 0.4^{\prime \prime}$

\section{GENERAL DESCRIPTION}

The DAC-12QZ is a low-cost/high performance 12-bit digitalto-analog converter designed for general purpose OEM applications. The completely self-contained module includes weighted resistor networks, monolithic $\mu \mathrm{DAC}$ current switches, temperature compensated reference and an externally programmable output amplifier. Performance specifications include $1 / 2$ LSB linearity error, $5 \mu \mathrm{sec}$ settling time for full scale conversion, $30 \mathrm{ppm} /{ }^{\circ} \mathrm{C}$ temperature coefficient and $20 \mathrm{ppm} / \%$ power supply rejection.

\section{$\mu$ DAC DESIGN}

This outstanding cost/performance ratio has been achieved by utilizing the popular AD550 $\mu$ DAC current switches as "secret ingredients". The use of monolithic quad current switches offers close inherent matching of switch characteristics and excellent temperature tracking as well as reasonably fast conversion speed. A hybrid resistor assembly of matched precision resistors and a thick film network is used in conjunction with the $\mu \mathrm{DAC}$ switches. Resistors provided include not only the weighting resistors but also the inter-quad attenuators, amplifier feedback resistors, etc. to assure close temperature tracking.

\section{INPUT CODING}

The internal $\mu \mathrm{DAC}$ switches of the binary and BCD models are driven directly by complementary input codes without need of a strobe. The complementary codes for each model are:

$$
\text { MODEL -F.S. Zero +F.S. }
$$

DAC-12QZ/BIN

111111111111000000000000 111111111111011111111111000000000000

DAC-12QZ/BCD

111111111111011001100110 111111111111101011111111011001100110
Information furnished by Analog Devices is believed to be accurate and reliable. However, no responsibility is assumed by Analog Devices for its use; nor for any infringements of patents or other rights of third parties which may result from its use. No license is granted by implication or otherwise under any patent or patent rights of Analog Devices.

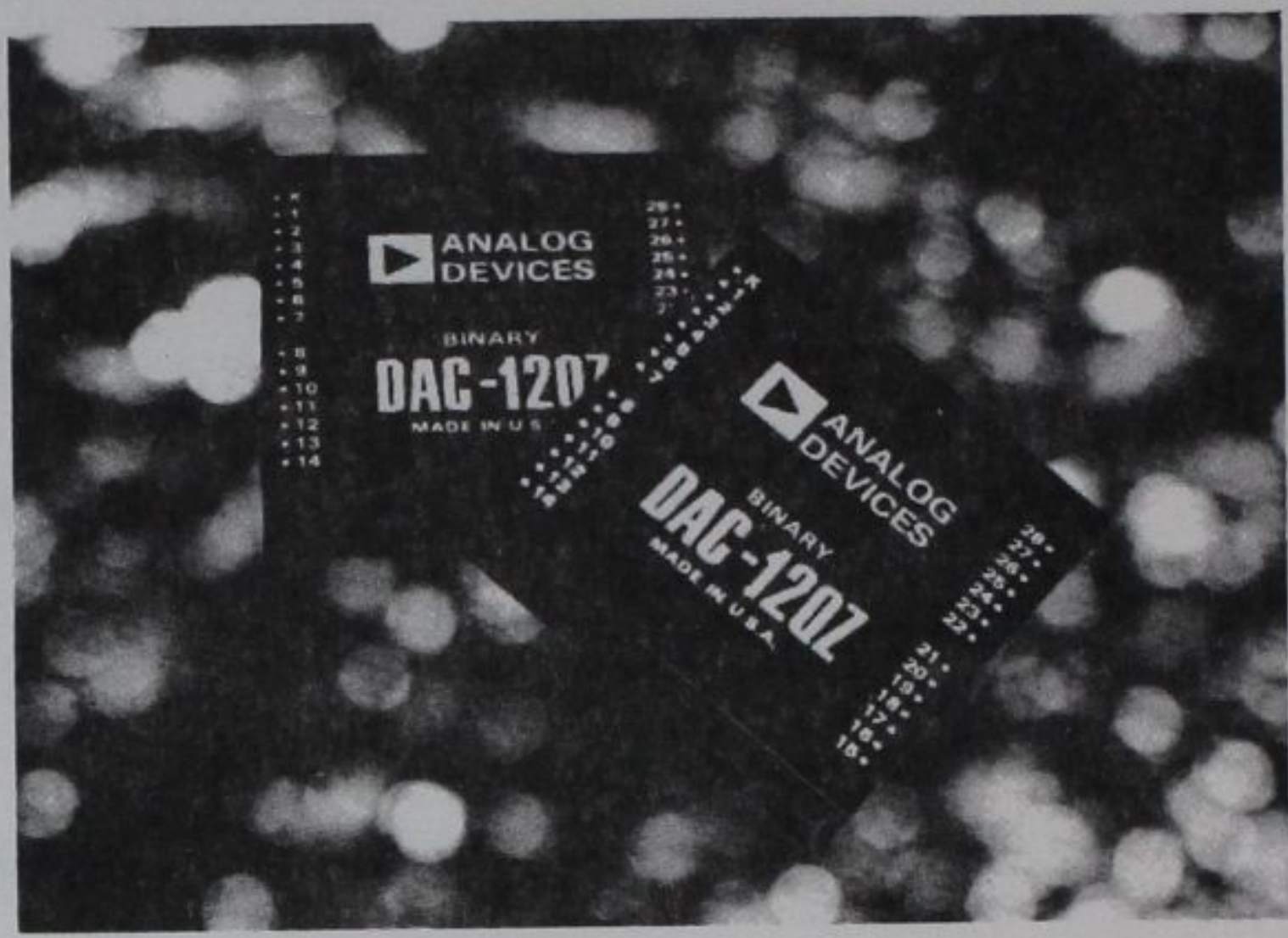

OUTPUT PROGRAMMING

The scale factor is programmed by connecting external jumpers between module pins. With either model, the user can select any one of five output ranges, including bipolar outputs. The choices are:

$$
\begin{array}{ll}
\text { Unipolar } & 0 \text { to }+5 \mathrm{~V}, 0 \text { to }+10 \mathrm{~V} \\
\text { Bipolar } & \pm 2.5 \mathrm{~V}, \pm 5 \mathrm{~V}, \pm 10 \mathrm{~V}
\end{array}
$$

The external jumpers at the module pins determine the output amplifier feedback resistance, allowing use of one $5 \mathrm{k}$ resistor, or both, either in series to provide $10 \mathrm{k}$, or parallel to provide $2.5 \mathrm{k}$. Offset of exactly one-half full scale for bipolar applications is provided by connecting another jumper to the summing junction of the output amplifier. To maintain constant load on the reference zener, the bipolar offset output should be grounded when using the module in a unipolar mode.

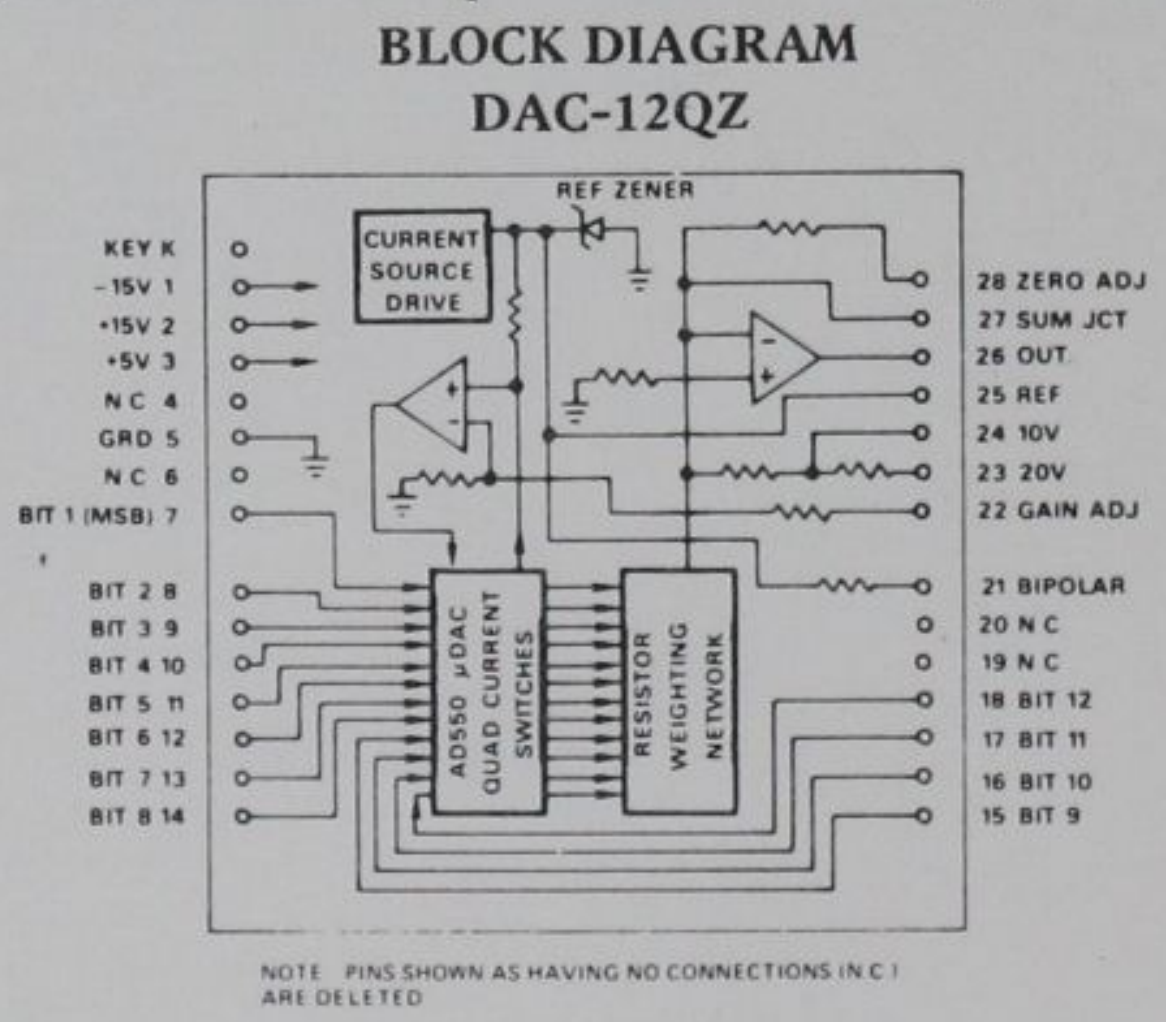

Route 1 Industrial Park; P.O. Box 280; Norwood, Mass. 02062 Tel: $617 / 329-4700$

West Coast TWX: 710/394-6577

Mid-West 


\begin{tabular}{|c|c|}
\hline RESOLUTION & 12 Bits \\
\hline $\begin{array}{l}\text { DIGITAL INPUTS } \\
\text { 'O' E }<+0.8 \mathrm{~V} \\
\text { ' } 1 \text { ' }+2 \mathrm{~V}<\mathrm{E}<+6 \mathrm{~V}\end{array}$ & $\begin{array}{l}\text { TTL Compatible } \\
\text { @ }-1.6 \mathrm{~mA} \\
\text { @ }+0.1 \mathrm{~mA} \text { (open input } \\
\text { equivalent to digital ' } 1 \text { ') }\end{array}$ \\
\hline $\begin{array}{l}\text { INPUT CODES } \\
\text { Unipolar } \\
\text { Bipolar }\end{array}$ & $\begin{array}{l}\text { Complementary Binary } \\
\text { Complementary BCD } \\
\text { Complementary Offset Binary } \\
\text { Complementary Offset BCD } \\
\end{array}$ \\
\hline $\begin{array}{l}\text { OUTPUT RANGES } \\
\text { (User Programmable) }\end{array}$ & $\begin{array}{l}0 \text { to }+5 \mathrm{~V} \text { @ } 10 \mathrm{~mA} \\
0 \text { to }+10 \mathrm{~V} \text { @ } 5 \mathrm{~mA} \\
\pm 2.5 \mathrm{~V}, \pm 5 \mathrm{~V} \text { @ } 10 \mathrm{~mA} \\
\pm 10 \mathrm{~V} \text { @ } 5 \mathrm{~mA}\end{array}$ \\
\hline OUTPUT IMPEDANCE & $0.02 \Omega$ \\
\hline $\begin{array}{l}\text { CONVERSION SPEED } \\
\text { Slewing Rate }\end{array}$ & $\begin{array}{l}5 \mu \mathrm{sec} \text { to } 0.01 \% \text { (for } 10 \mathrm{~V} \text { step) } \\
20 \mathrm{~V} / \mu \mathrm{sec}\end{array}$ \\
\hline LINEARITY ERROR & $\pm 1 / 2$ LSB \\
\hline $\begin{array}{l}\text { TEMPERATURE COEFFICIENT } \\
\text { Gain } \\
\text { Zero } \\
\text { Differential Linearity } \\
\end{array}$ & $\begin{array}{l} \pm 30 \mathrm{ppm} /{ }^{\circ} \mathrm{C} \text { of Reading, } \max \\
\pm 50 \mu \mathrm{V} /{ }^{\circ} \mathrm{C} \text { (Unipolar), } \max \\
\pm 100 \mu \mathrm{V} /{ }^{\circ} \mathrm{C} \text { (Bipolar), } \max \\
\pm 10 \mathrm{ppm} /{ }^{\circ} \mathrm{C} \text { F.S., max }\end{array}$ \\
\hline $\begin{array}{l}\text { TEMPERATURE RANGE } \\
\text { Operating } \\
\text { Storage }\end{array}$ & $\begin{array}{l}0 \text { to }+70^{\circ} \mathrm{C} \\
-55^{\circ} \mathrm{C} \text { to }+125^{\circ} \mathrm{C}\end{array}$ \\
\hline POWER REQUIREMENTS & $\begin{array}{l}+15 \mathrm{~V} \pm 5 \% \text { @ } 25 \mathrm{~mA} \\
-15 \mathrm{~V} \pm 5 \% \text { @ } 30 \mathrm{~mA} \\
+5 \mathrm{~V} \pm 10 \% \text { @ } 35 \mathrm{~mA} \\
\end{array}$ \\
\hline $\begin{array}{l}\text { POWER SUPPLY SENSITIVITY } \\
\text { Gain } \\
\text { Zero } \\
\end{array}$ & $\left.\begin{array}{l} \pm 20 \mathrm{ppm} / \% \\
\pm 5 \mathrm{ppm} / \%\end{array}\right\} \begin{array}{l} \pm 15 \mathrm{~V} \text { only; } \\
\text { tracking supplies }\end{array}$ \\
\hline $\begin{array}{l}\text { ADJUSTMENTS (USER PROVIDED) } \\
\text { Gain }(20 \mathrm{k}, 20 \text { turn pot) } \\
\text { Zero }(20 \mathrm{k}, 20 \text { turn pot) }\end{array}$ & $\begin{array}{l} \pm 0.3 \% \text { F.S. } \\
\pm 30 \mathrm{mV}\end{array}$ \\
\hline OUTLINE DIMENSIONS & $2^{\prime \prime} \times 2^{\prime \prime} \times 0.400^{\prime \prime}$ \\
\hline $\begin{array}{l}\text { PRICES } \\
(1-9) \\
(10-24) \\
(25-99) \\
(100+)\end{array}$ & $\begin{array}{l}\$ 79 \\
\$ 59 \\
\$ 49 \\
\$ 47\end{array}$ \\
\hline
\end{tabular}

${ }^{1}$ A mounting board complete with trim pots and supplied with mating connector is available at extra cost. Order Part No. 4516. Price $\$ 40$.

Pin Socket - 2-330808-8, 25 required - $\$ .20$ each.

Specifications subject to change without notice.

ORDERING GUIDE :

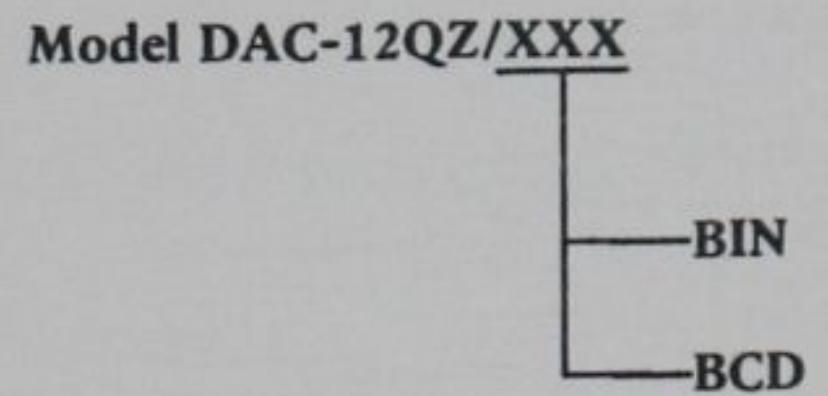

OUTLINE DIMENSIONS (In Inches) AND PIN CONNECTIONS
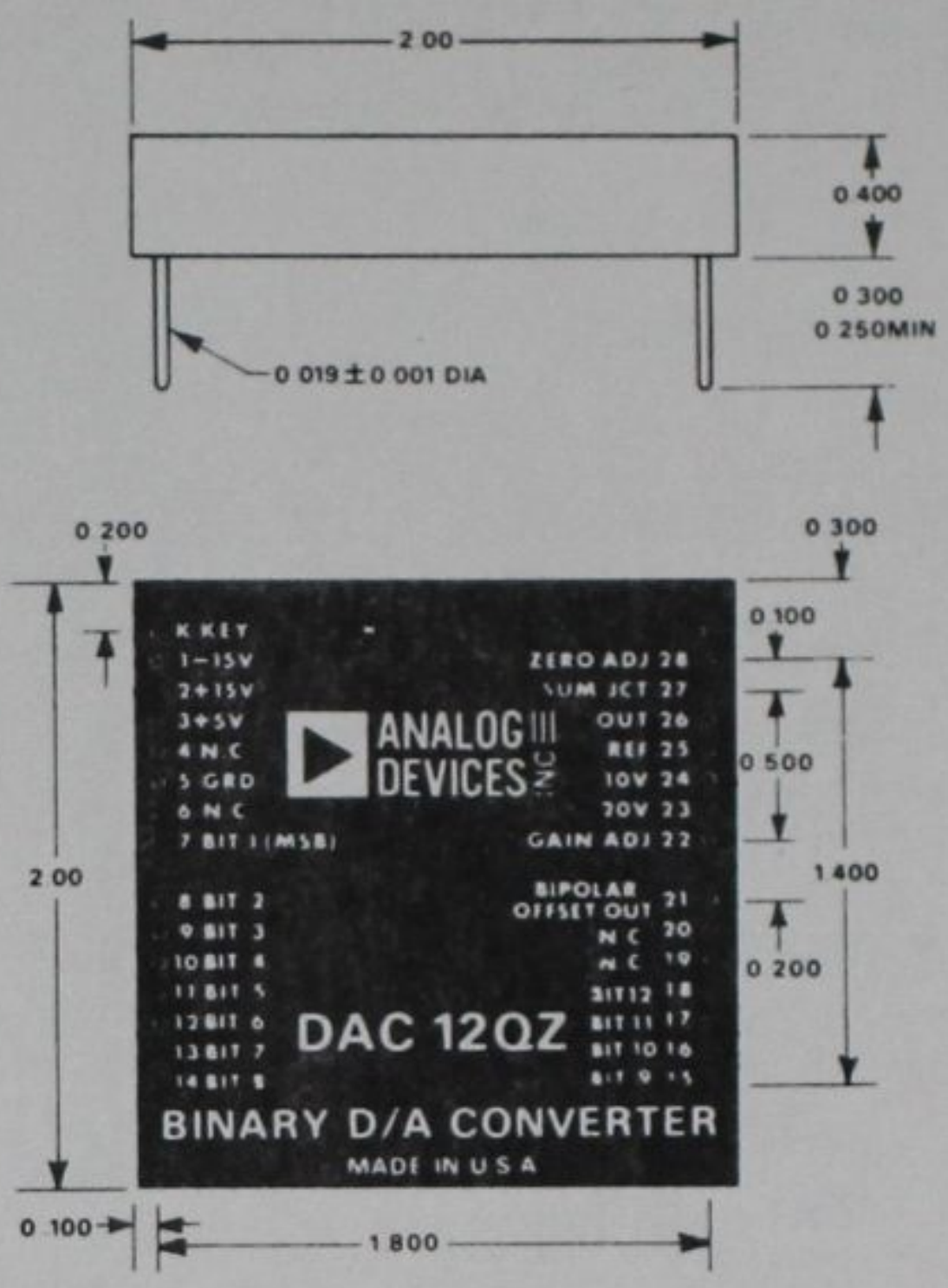

TOP VIEW

\section{POTENTIOMETER CONNECTIONS}

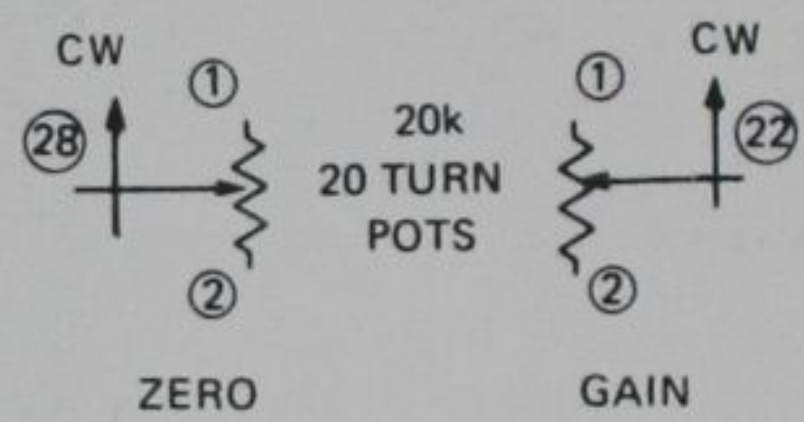

OUTPUT PROGRAMMING

\begin{tabular}{|c|c|c|c|}
\hline Output Range & \multicolumn{3}{|c|}{ External Pin Connections } \\
\hline $\pm 2.5 \mathrm{~V}$ & $21,23, \& 27$ & $24 \& 26$ & \\
\hline $\pm 5 \mathrm{~V}$ & $21 \& 27$ & $24 \& 26$ & \\
\hline $\pm 10 \mathrm{~V}$ & $21 \& 27$ & $23 \& 26$ & \\
\hline$+5 \mathrm{~V}$ & $23 \& 27$ & $24 \& 26$ & $21 \& 5$ \\
\hline$+10 \mathrm{~V}$ & $24 \& 26$ & $21 \& 5$ & \\
\hline
\end{tabular}

Connect pins as indicated for selected outpul.

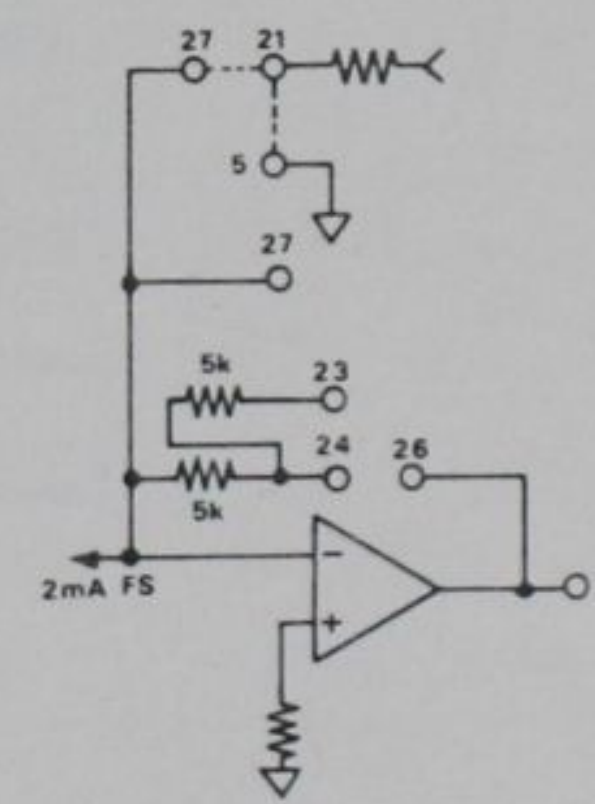

Figure 1. Output Amplifier 
APPENDIX B: DETAILS OF DIGITAL RECORDING SYSTEM 
Table BI

System Specifications

\section{Item \\ System \\ Primary power \\ Environment \\ Dimensions \\ Datacoupler}

Data inputs

Modes

INTERVALOMETER

Scan length

INTVL pulse output

INHI, 2, and 3 pulse outputs

Digital Clock Magnetic Tape Recorder
$115 \pm 10$ percent, VAC, $60-400 \mathrm{~Hz}$, single phase Temperature: $0^{\circ} \mathrm{C}$ to $50^{\circ} \mathrm{C}$ Humidity: 10-90 percent (noncondensing)

Height: 64.5 in.

Width: 23 in.

Depth: 30 in.
Specification

Format: 12-bit binary

Amplitude: $\operatorname{logic} 1=+5 \mathrm{VDC}$

logic $0=0$ VDC

Number of channels: 18 (wired for 32 to allow future expansion)

Four operating modes

Interval between scans is switch-selected as follows: Time increments: seconds, minutes, hours Multiplier range: 00 to 99

From 1 to 18 channels (expandable to 32 ). Scan always begins with channel 0 . Last channel to be included in scan is switch-selected

Appears at connector J220

Frequency: Determined by INTERVALOMETER switch settings. Pulse occurs at beginning of interval

Pulse width: Approximately $10 \mu \mathrm{sec}$

Amplitude: 0 to $+5 \mathrm{VDC}$; positive true

Appear at connectors J22l thru J223; all three outputs are identical. INH pulse appears while Datacoupler storage registers are being loaded with input data.

Pulse width: Approximately $40 \mu \mathrm{sec}$ Amplitude: 0 to $+5 \mathrm{VDC}$; positive true

Refer to Model 3350-203 Instruction Manual

Refer to Cipher Model 100 Instruction Manual 
Data Input Connector Pin Assignments

\begin{tabular}{|c|c|c|c|}
\hline \multicolumn{2}{|c|}{ First Channel } & \multicolumn{2}{|c|}{ Second Channel } \\
\hline Pin & Binary Bit & $\underline{\text { Pin }}$ & Binary Bit \\
\hline 20 & 1 & 12 & 1 \\
\hline 19 & GND & 11 & GND \\
\hline 22 & 2 & 14 & 2 \\
\hline 21 & GND & 13 & GND \\
\hline 44 & 4 & 28 & 4 \\
\hline 43 & GND & 27 & GND \\
\hline 46 & 8 & 30 & 8 \\
\hline 45 & GND & 29 & GND \\
\hline 48 & 16 & 32 & 16 \\
\hline 47 & GND & 31 & GND \\
\hline 50 & 32 & 34 & 32 \\
\hline 49 & GND & 33. & GND \\
\hline 24 & 64 & 16 & 64 \\
\hline 23 & GND & 15 & GND \\
\hline 26 & 128 & 18 & 128 \\
\hline 25 & GND & 17 & GND \\
\hline 52 & 256 & 36 & 256 \\
\hline 51 & GND & 35 & GND \\
\hline 54 & 512 & 38 & 512 \\
\hline 53 & GND & 37 & GND \\
\hline 56 & 1024 & 40 & 1024 \\
\hline 55 & GND & 39 & GND \\
\hline 58 & 2048 & 42 & 2048 \\
\hline 57 & GND & 41 & GND \\
\hline
\end{tabular}


APPENDIX C: SAMPLES OF PREPROCESSOR OUTPUT

$\mathrm{Cl}$ 
LITTLE RIVER MODEL

\section{VELOCITY TAPE READ AND DATA SCALE}

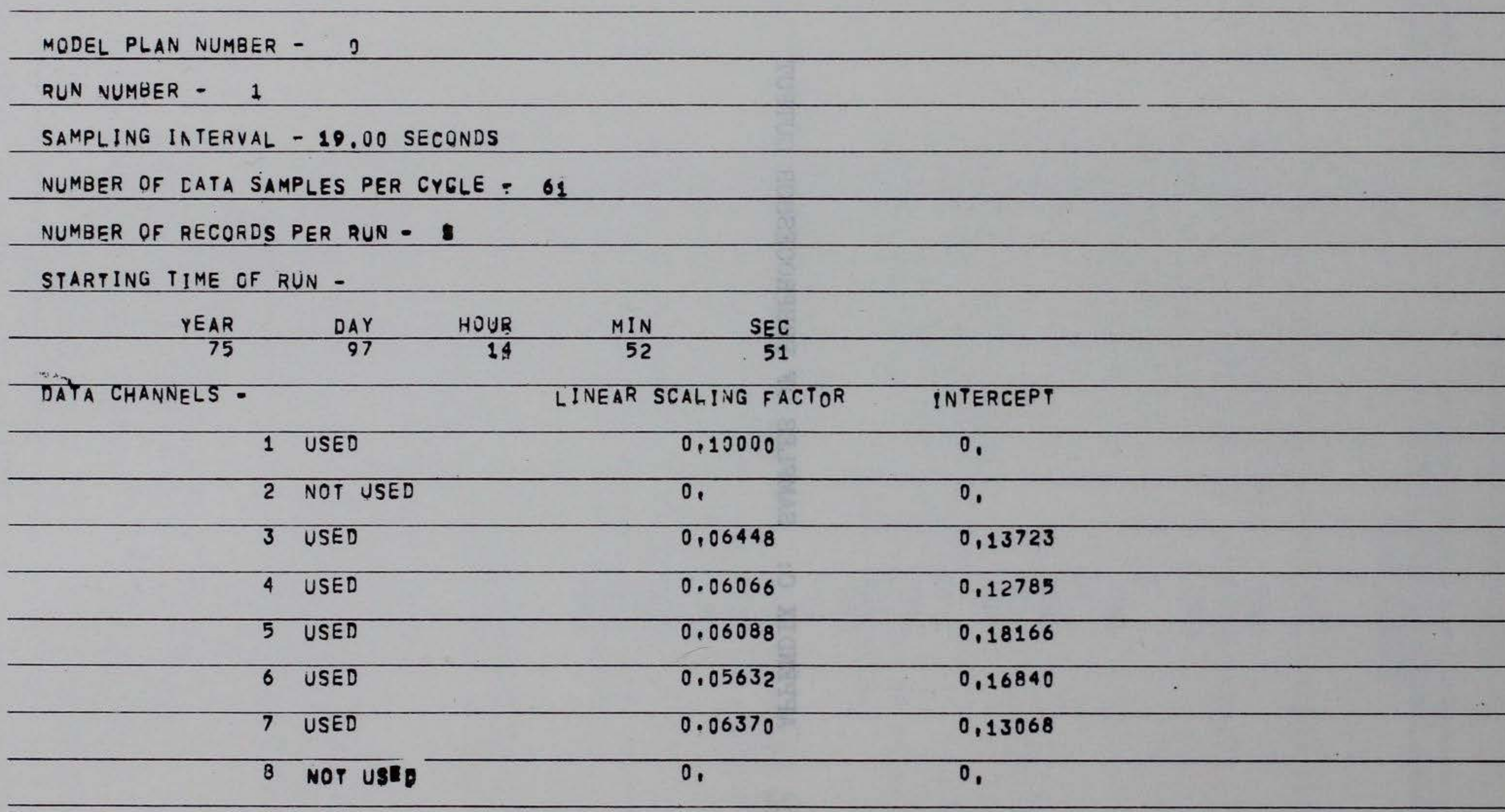


LUTLE RIVER MODEL

PLAN NO. 0 RUN ND, 1

CHANNEI NO. 3

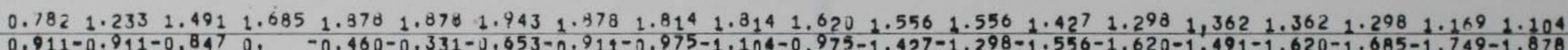

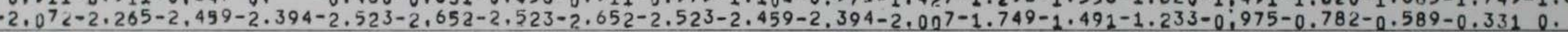

$-0.524$

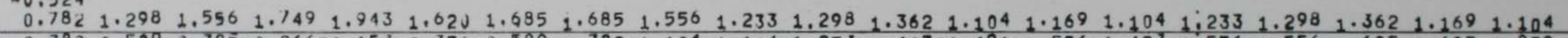

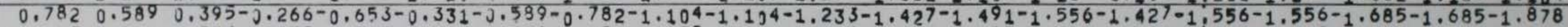

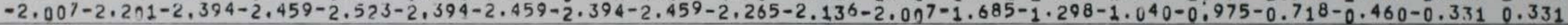

0,653

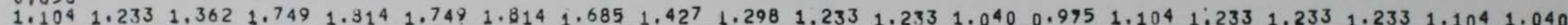

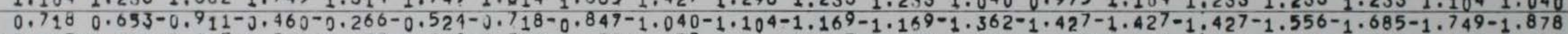

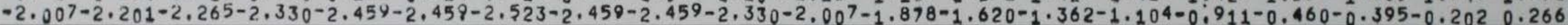
0,718 
APPENDIX D: SAMPLES OF PROCESSOR OUTPUT 
MODEL PLAN NUMBER - 0

RUN NUMBER - 1

SAMPLING INTERVAL - 19.00 SECQNOS

NUMBER OF DATA SAMPLES PER CYELE - 61

NUMBER OF RECORDS PER MUN -

STARTING TIME OF RUN -

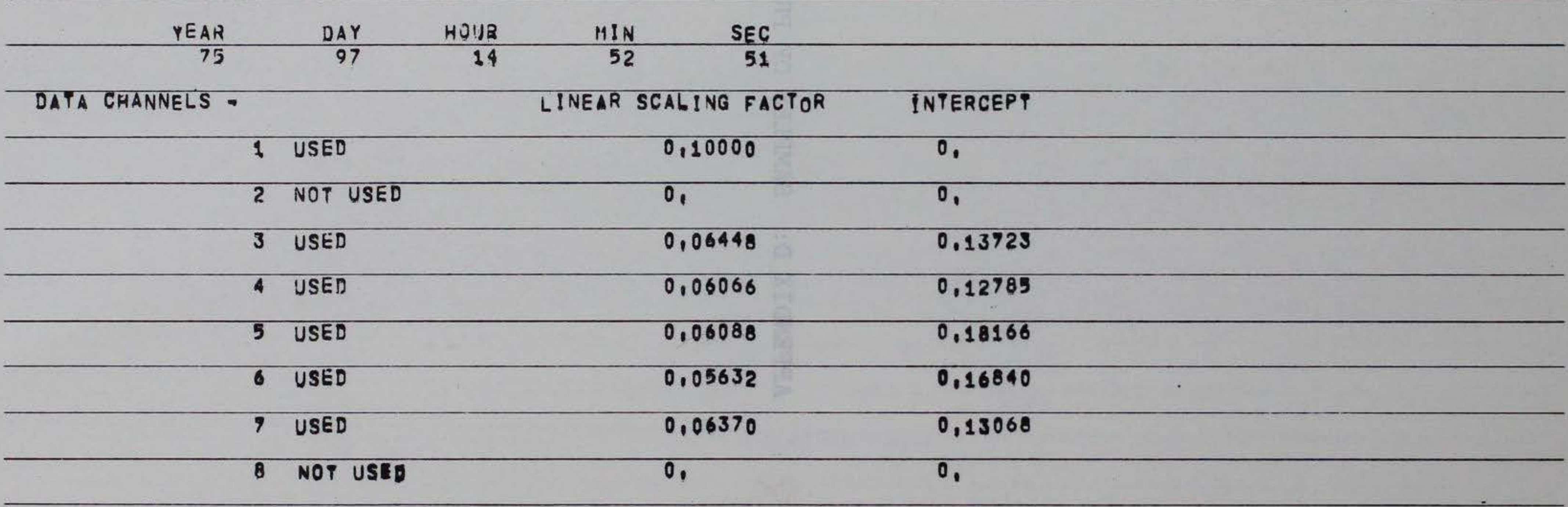


WITTLE RIVER MQDEL

PLAN NOR 0 RUN NO. 1

CHAMNEL NO, 1

MODEL CLOCR

$3.0003 .0003 .5003,5003.5004 .0006 .000 \quad 6.5006,5005.0005,0005.0005 .5005 .5006 .0006,0006.0006 .5006 .5007 .000$ $7,0007.0007,5807,5008.0008 .0008 .000 \quad 0.5008,5009.0009,0009.500 \quad 0.500 \quad 0,50010.00010,00010.50010 .50010 .50011 .000$ $11.00011 .50011,50018.50012 .00012 .0000$ 0 0 . $0.5000 .500 \quad 0.5001 .0001 .0001 .5001 .5001 ; 5002.0002 .0002 .5002 .500$ 3,000

$3.0003 .0003 .5803 .5004 .0004 .000 \$ 8000 \$ .500 \quad \$ .500 \quad 5.0005,0005.0005 .5005 .5006 .0006,0006.5006 .5006 .5007 .000$

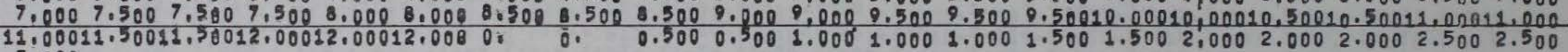
3,000

$3.0003 .0003 .5003 .5004 .0004 .0004 .5004 .500 \quad 4.5005 .0005,0005.5005 .5005,5006.0006,0006,5006.5006 .5007 .000$ $1.0007 .5007 .5808 .0008 .0008 .0008 .5008 .5009 .0009 .0089 .0009 .5009 .50010 .00010 .00010,00010.50010 .50011 .00011 .000$ 11.00011 .50011 .50012 .00012 .0000 . 
LITTLE RIVER MODEL

PLAN NOr 0 RUN NO. 1

CHANNEL NO, 3

POLYNOMIAL COEFFICIENTS FOR A*X * B

POLYNOMIAL COEFFICIENTS POR A X * B

POLYNOMIAL COEFFICIENTS TOR A XX B

POLYNOMIAL COEFFICIENTS FOR A.X B

POLYNOMIAL COEFFICIENTS POR AEX $\bullet$
$A=-0.24833 \quad B=0.12596$

$A=0.37729 \quad B=-22.59090$

A. $-0.23544 \quad B=20.17177$

$A \quad 0.33860 \quad D=-40.06315$

$A=0.27412 \quad B .40 .22693$

DATA NOT EDITED

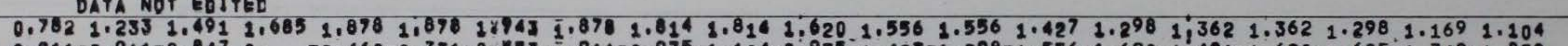

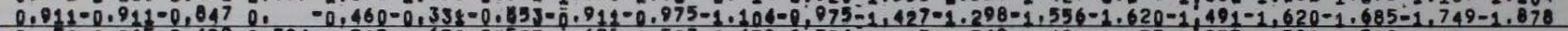
$=2.072-2.265-2.499-2.394-2.523-2.652-2.523-2.652-2.523-2.459-2.394-2.007-1.749-1.491-1.233-0.975-0.782-0.589-0.3310$.

$-0.524$

DATA EBITED

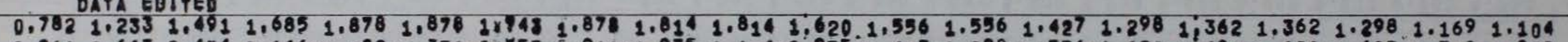
$0.0110 .6630 .4140 .166-0.082-0,338-0.653-0.911-0.975-1.104=0,975-1.427-1.298-1.556-1.620-1,491-1,620-1.685-1.749-1.878$

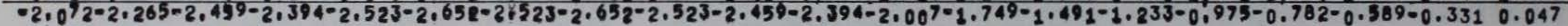
0.424

DATA NOT EBITED

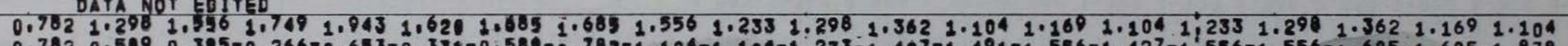

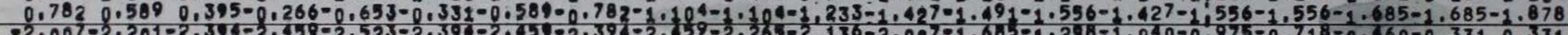
0.653

DATA EDITEB

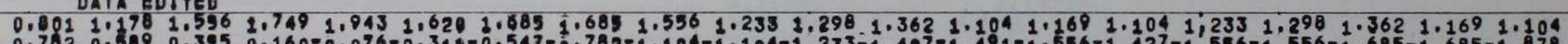
$0.7820 .5890 .3950 .160=0.076-0,312-0.542-0,782-1.104-1.104-1.233-1.427-1,491-1.556-1.427-1,556-1.556-1.685-1.685-1.878$

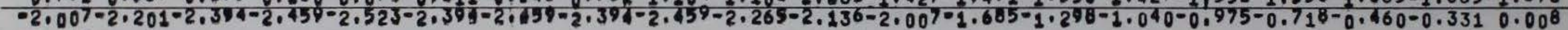
0.347

DATA NOT EDITED

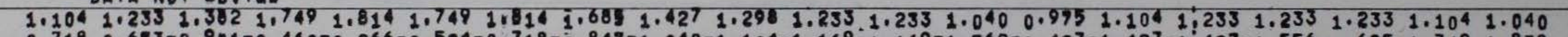
$0.7180 .653-0,911-0.460=0,266-0,529-0,718=0.847-1,040-1.104-1,169-1,169-1.362-1.427-1.427-1 ; 427-1,556-1.685-1.749-1.878$

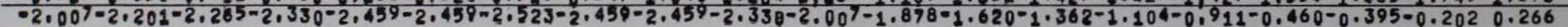
0.718

DATA EDITED

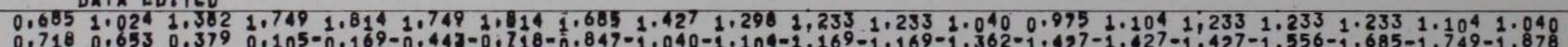
$0,7180.6530 .3790 .105-0.169-0,443-0.218-0.047-1.040-1.104-2,169-1.169-1.362-1.427-1.427-1,427-1.556-1.685-1.749-1.878$ 0.718 
LITTLE RIVER MODEL

CHANNEL NO. 3

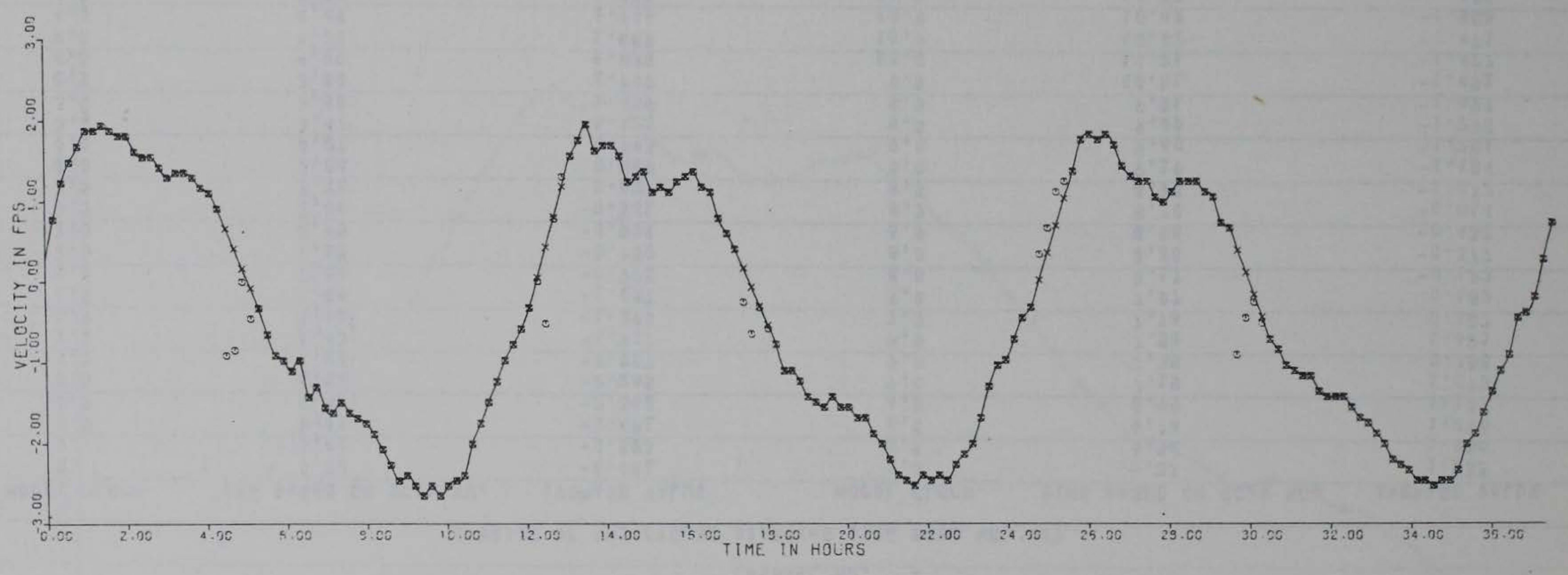


LITTLE RIVER MODEL

PLAN NO, 0 RUN NO. 1

CWANNEL NO, 3

AVEBAGE OF PWO CYCLES STARYING WITH SGAN NO, 47

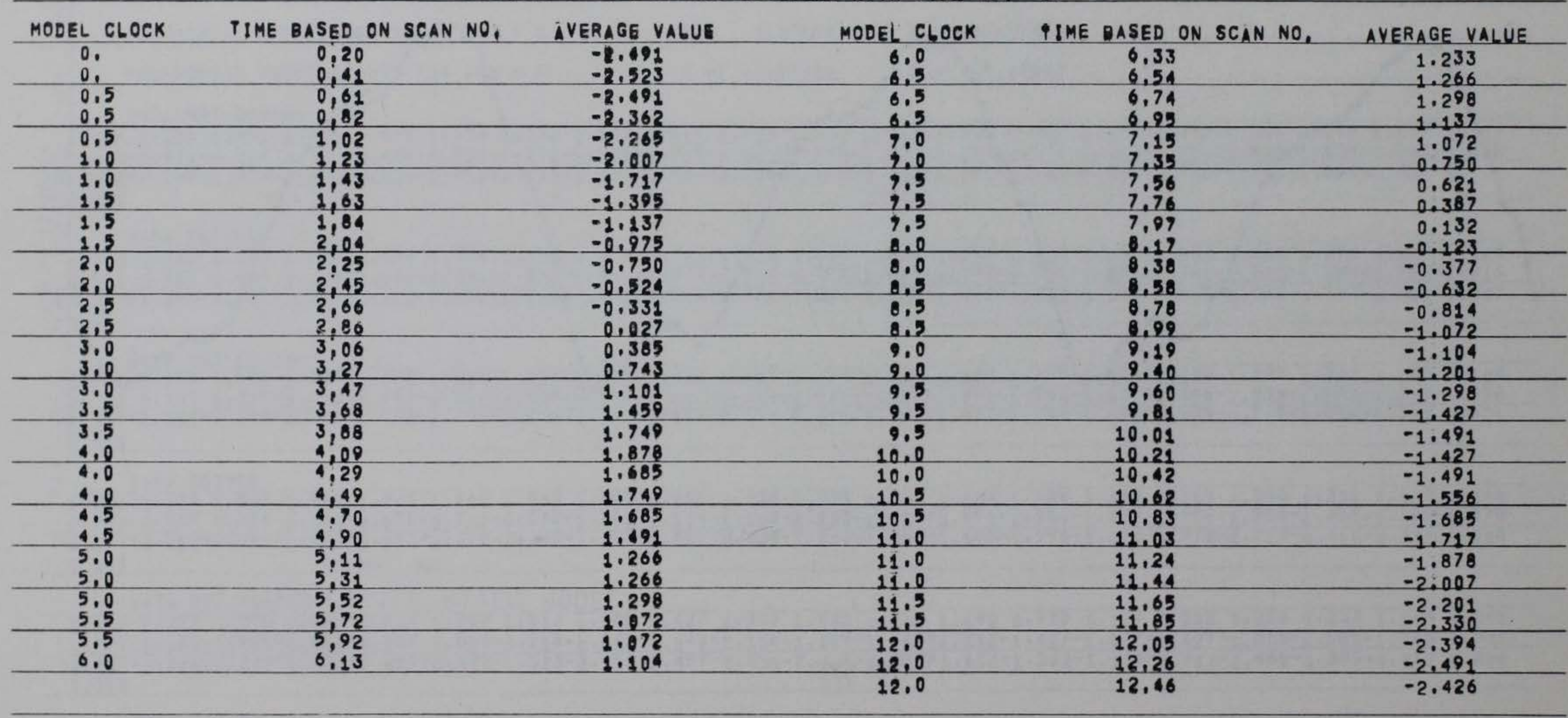




\section{LITTLE RIVER MODEL.}

CHANNEL. NO, 3

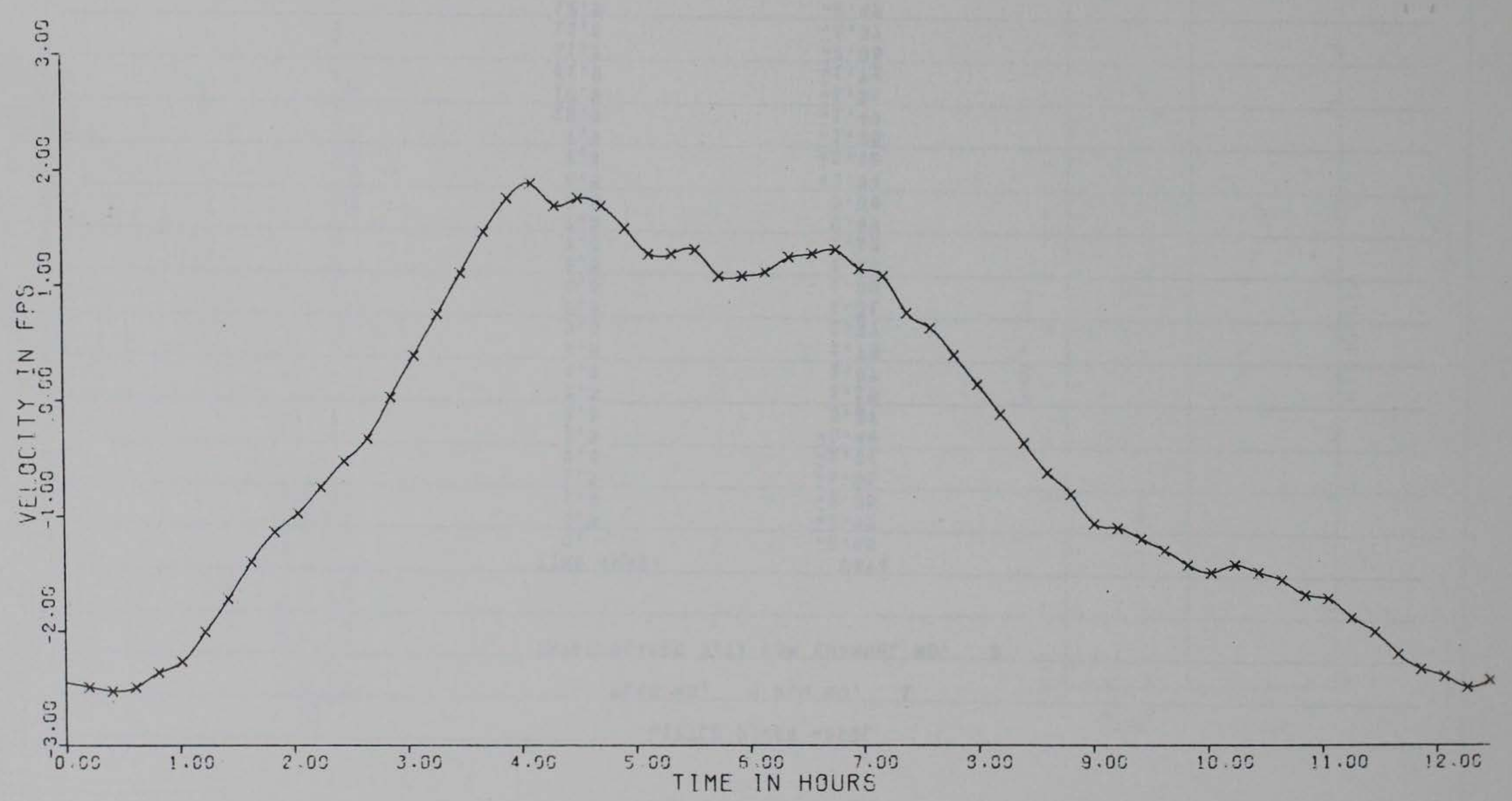


LITYLE RIVER MODEL

PLAN RO, O RUN NO, I

INTERPOLATED DATA FOR CHANNEL NO, 3

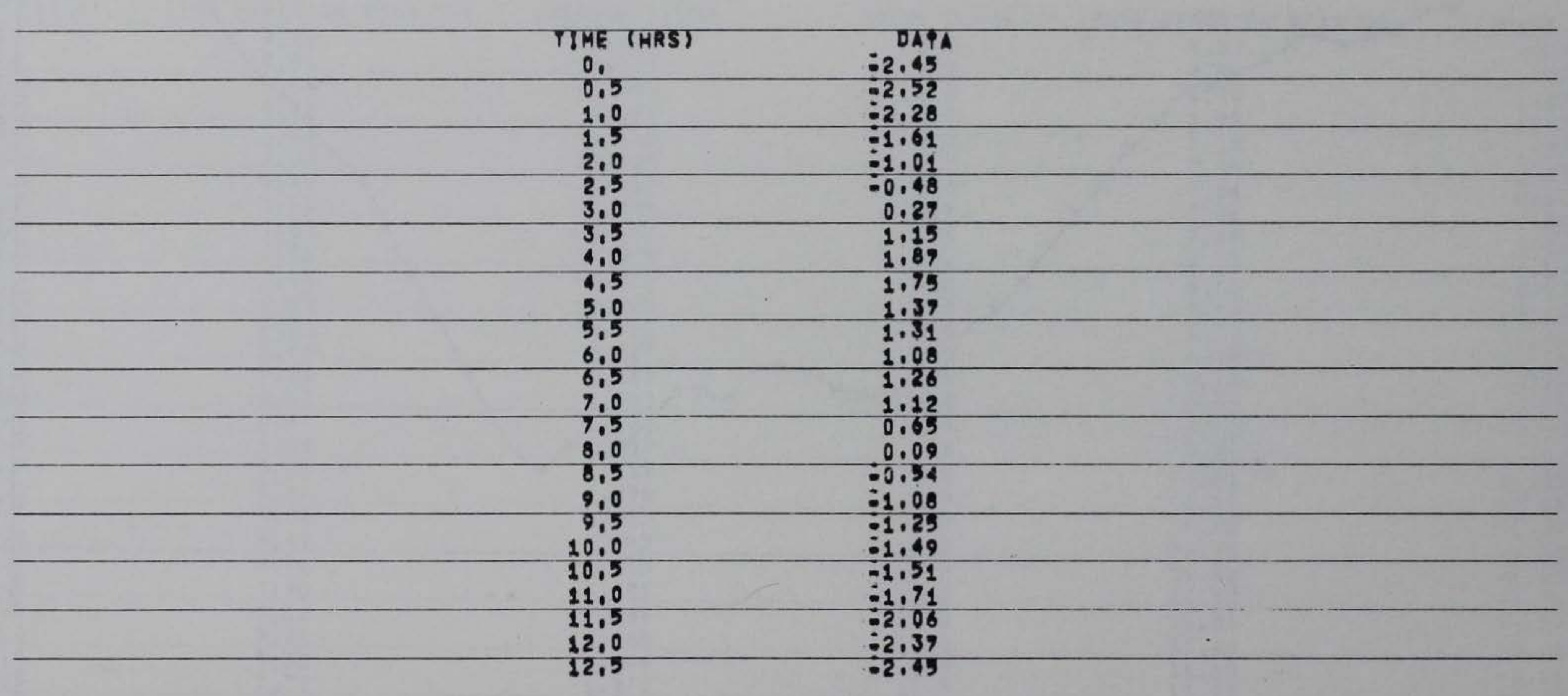




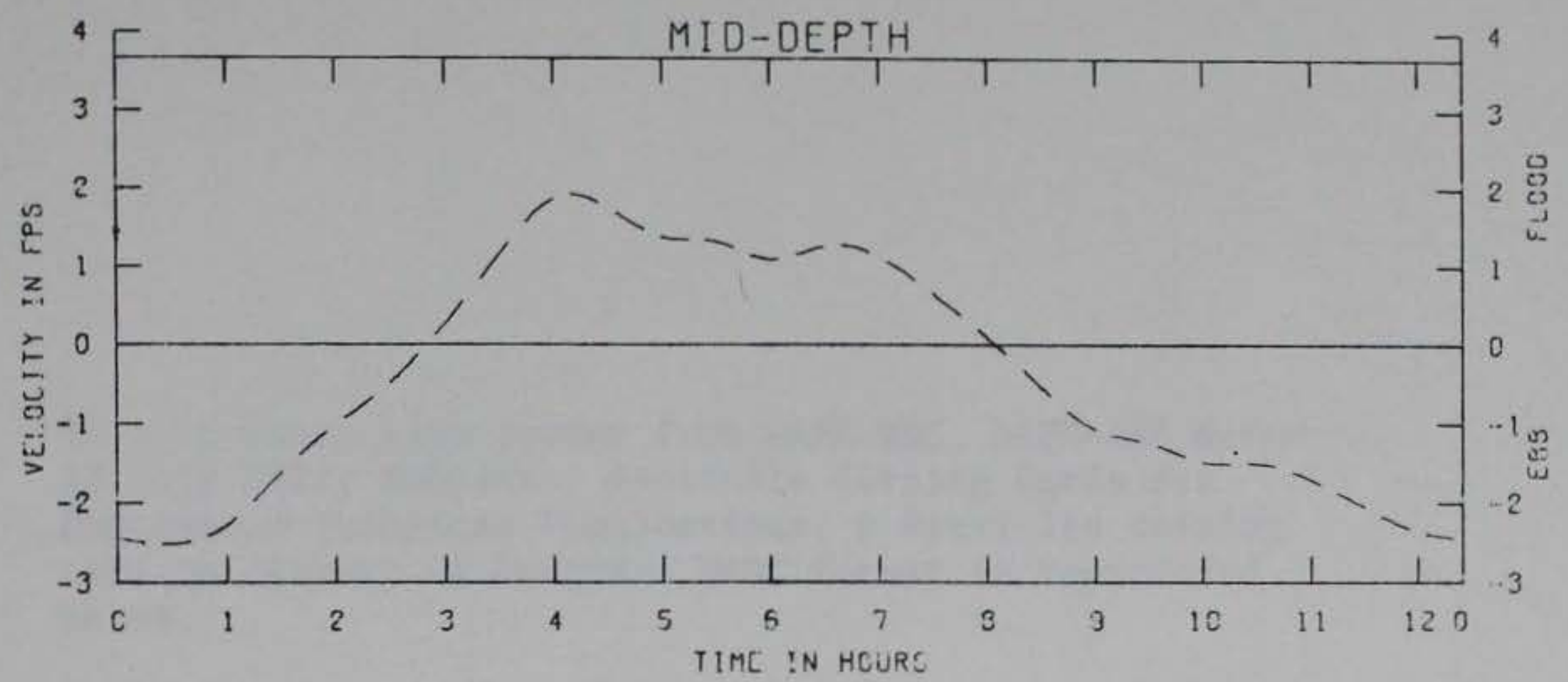

TEST CONEITIONS

TRIAL RUN FOR GNAL ISIS PROCRAM OEVELOPMENT

1. EGENC

MOOE: $\quad \ldots-$
HTTIE RIVER TNLET MOOE:

VELOCITY DATA ANALYSIS

TRIAL RUN TO CHECK

VELOCITY GNALYSIS 